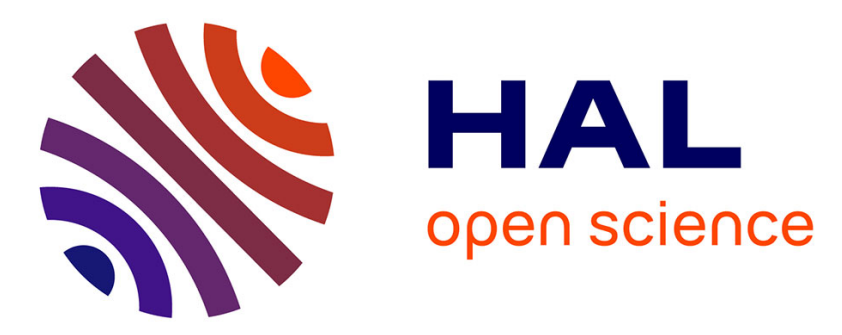

\title{
Toward a Better Determination of Turbulent Air-Sea Fluxes from Several Experiments
}

Alain Weill, Laurence Eymard, G. Caniaux, Danièle Hauser, S. Planton, H. Dupuis, Aurore Brut, C. Guérin, P. Nacass, A. Butet, et al.

\section{- To cite this version:}

Alain Weill, Laurence Eymard, G. Caniaux, Danièle Hauser, S. Planton, et al.. Toward a Better Determination of Turbulent Air-Sea Fluxes from Several Experiments. Journal of Climate, 2003, 16 (4), pp.600 - 618. 10.1175/1520-0442(2003)0162.0.CO;2 . hal-01651327

\section{HAL Id: hal-01651327 https://hal.science/hal-01651327}

Submitted on 10 Jan 2020

HAL is a multi-disciplinary open access archive for the deposit and dissemination of scientific research documents, whether they are published or not. The documents may come from teaching and research institutions in France or abroad, or from public or private research centers.
L'archive ouverte pluridisciplinaire HAL, est destinée au dépôt et à la diffusion de documents scientifiques de niveau recherche, publiés ou non, émanant des établissements d'enseignement et de recherche français ou étrangers, des laboratoires publics ou privés. 


\title{
Toward a Better Determination of Turbulent Air-Sea Fluxes from Several Experiments
}

\author{
A. Weill, ${ }^{*}$ L. Eymard, ${ }^{*}$ G. Caniaux, ${ }^{+}$D. Hauser,$*$ S. Planton ${ }^{+}$H. Dupuis, ${ }^{\#}$ A. Brut ${ }^{+}$C. Guerin, ${ }^{*}$ \\ P. Nacass, ${ }^{@}$ A. Butet, ${ }^{+}$S. Cloché,* R. Pedreros,, P. Durand, ${ }^{+}$D. Bourras, ${ }^{+}$H. Giordani, ${ }^{+}$ \\ G. LACHAUd, ${ }^{+}$AND G. Bouhours ${ }^{+}$ \\ *CETP/IPSL/CNRS, Velizy, France \\ ${ }^{+}$Météo-France/CNRM, Toulouse, France \\ ${ }^{\#}$ DGO, Talence, France \\ $@_{\text {Météo-France/CAM, Bretigny, France }}$ \\ $\&_{\text {NASA Jet Propulsion Laboratory, Pasadena, California }}$
}

(Manuscript received 1 November 2001, in final form 27 May 2002)

\section{ABSTRACT}

An accurate determination of turbulent exchanges between the ocean and the atmosphere is a prerequisite to identify and assess the mechanisms of interaction that control part of the variability in the two media over a wide range of spatial and temporal scales. An extended dataset for estimating air-sea fluxes (representing nearly $5700 \mathrm{~h}$ of turbulence measurements) has been collected since 1992 during six dedicated experiments performed in the Atlantic Ocean and the Mediterranean Sea. This paper presents the methodology used through the successive experiments to progress in this field. The major developments concern (i) flux instrumentation, with the deployment of a microwave refractometer to get the latent heat flux in most meteorological conditions; (ii) the analysis of airflow distortion effects around the ship structure and sensors through both computational fluid dynamics and physical simulations in a water tank, then the derivation of correction for these effects; (iii) the application of both inertial dissipation and eddy-correlation methods from the various experiments, allowing the authors to assess and discuss flux-determination methods on ships, and particularly bulk parameterization; (iv) the validation and analysis of mesoscale surface flux fields from models and satellites by using ship data, showing some deficiencies in operational model fields from ECMWF, the need of high-quality fluxes to interpret oceanatmosphere exchanges, and the potential advantage of satellite retrieval methods. Further analysis of these datasets is being performed in a unique database (the ALBATROS project, open to the international scientific community). It will include refinement of airflow distortion correction and reprocessing of earlier datasets, the investigation of fluxes under specific conditions (low wind), and the effect of sea state among others. It will also contribute to further validation and improvements of satellite retrievals in various climatic/meteorological conditions.

\section{Introduction}

Sea surface fluxes characterize the transfer of energy and momentum at the sea surface. The development of climate and predictability studies, that consider the ocean as a key component of the climate system, has put emphasis on the determination of these fluxes. Ocean-atmosphere interactions, indeed, strongly control the energy and water cycle in the atmosphere, and the dynamics of the ocean. Knowledge of these fluxes is thus essential to identify and assess the forcing and coupling mechanisms that modulate the atmospheric and oceanic variability from the timescale of local processes to the timescales of climate variability, and particularly those of anthropogenic climate change. The use of satellite or numerical models as general circulation models (GCMs) for estimating fluxes at larger spatial scales is

Corresponding author address: Dr. Laurence Eymard, CETP/IPSL/ CNRS, 10-12 av. De l'Europe, 78140 Velizy, France.

E-mail: laurence.eymard@cetp.ipsl.fr also a crucial need. The main question is to find efficient and relevant methods to get precise turbulent fluxes and to relate these fluxes to mean atmospheric parameters, following the parameterization method proposed by Businger (1972).

Many problems still remain in the measurement of air-sea fluxes, specially at low or high wind speed or under strong stratification, the dependence and effects of the sea state (reviewed, e.g., by Komen et al. 1998); in the various methods used to measure turbulent parameters on board moving platforms and the need to correct them (Yelland et al. 1998); but also in the use of parameterizations (Garatt 1992), and finally in the way to represent fluxes in numerical models (Smith et al. 1999; Renfrew et al. 2002) or climatologies (Weller and Anderson 1996; Josey 2001).

These questions were raised through a vast program we started as soon as 1992, devoted to air-sea fluxes and their parameterization. This paper is aimed at presenting the methodology that was followed throughout 
TABLE 1. Main characteristics and means during the experiments.

\begin{tabular}{|c|c|c|c|c|}
\hline Experiment & Location & Period & Ship & Remarks \\
\hline SOFIA & $\begin{array}{l}\text { NE Atlantic } \\
\text { Canary Basin }\end{array}$ & Jun 1992 & Le Suroît & \\
\hline SEMAPHORE & $\begin{array}{l}\text { NE Atlantic } \\
\text { Canary Basin }\end{array}$ & 7 Oct-15 Nov 1993 & Le Suroît & $\begin{array}{l}\text { Two planes, buoys, drifters, and a } \\
\text { hydrological network (three } \\
\text { ships: Le Suroit, D'Entrecas- } \\
\text { teaux, and Pr. Stockman) }\end{array}$ \\
\hline CATCH & $\begin{array}{l}\text { NW Atlantic } \\
\text { Newfoundland Basin }\end{array}$ & 8 Jan-1 Mar 1997 & Le Suroît & $\begin{array}{l}\text { Two ships (Le Suroît and Knorr), } \\
\text { drifters, and a hydrological net- } \\
\text { work }\end{array}$ \\
\hline FETCH & $\begin{array}{l}\text { Mediterranean Sea } \\
\text { Gulf of Lion }\end{array}$ & 13 Mar-15 Apr 1998 & L'Atalante & $\begin{array}{l}\text { Two planes, buoys, and a hydrolog- } \\
\text { ical network }\end{array}$ \\
\hline EQUALANT99 & Equatorial Atlantic & 15 Jul-20 Aug 1999 & La Thalassa & Hydrological network \\
\hline POMME & $\begin{array}{l}\text { NE Atlantic } \\
\text { Iberic Basin }\end{array}$ & 2 Feb-11 May 2001 & L'Atalante & $\begin{array}{l}\text { Moored buoy, drifters, and a hydro- } \\
\text { logical network (two ships: } \\
\text { L'Atalante and D'Entrecasteaux) }\end{array}$ \\
\hline
\end{tabular}

the various field experiments and the results obtained. Initially the objectives were the following:

1) to develop a set of instruments able to carry out reliable flux measurements on research ships in all weather;

2) to develop a calculation method adapted to measurement of fluxes on mobile platforms;

3) to develop a unified parameterization of turbulent fluxes; and

4) to determine fluxes on larger time- and space scales than in situ local measurement, which is a crucial need for numerical models.

After several in situ experiments performed in the Atlantic Ocean and Mediterranean Sea, a certain number of results were obtained and published. However, new questions arose after the first two experiments. It appeared essential to improve the methods classically used for measuring fluxes as the inertial-dissipation (ID) method. Complementary flux measurements (from planes or buoys), led us to develop adequate instrumentation allowing the calculation of fluxes by the eddy-correlation method (ECM). In the same way, measurements on a mobile platform showed the necessity to take into account the flow distortion around the ship used as well as around the sensors. Finally, taking into account the importance of the dataset collected and the large diversity of the weather and oceanic situations met during these experiments, a standardization of data processing was necessary. This step led us to recently create a database, initiated in the framework of AUTOFLUX (the European project for the measurement and parameterization of turbulent fluxes over sea; Larsen et al. 2000), which contributes to international efforts such as the National Oceanographic and Atmospheric Administration (NOAA) Environmental Technology Laboratory (ETL) database (Fairall et al. 2001) and the SEAFLUX (Curry 2000) project. The AUTOFLUX Linked Base for Atmospheric Transfer at the Ocean Surface (ALBATROS) database, opened to the international community, makes it possible to gather significant rough data files, to develop standard methods for calculating fluxes, to initiate new studies, and to derive a unified parameterization for turbulent fluxes.

In section two, we summarize the various experiments carried out during this program. Section 3 gives some details on the instruments used or specifically developed for measuring fluxes. Section 4 addresses the problem of airflow distortion. New results are presented in section 5 concerning the development of flux parameterization, based on the multiexperiment database. Section 6 presents the methodology for getting and assessing fluxes at larger space scales than that of in situ measurements. The conclusions and future work are drawn in section 7 .

\section{The experiments}

In this section, the main features of the various experiments carried out since 1992 are summarized. Table 1 gathers the main characteristics of the six campaigns. Figure 1 presents the trajectory of the research vessels and Fig. 2 is a synthesis of the meteo-oceanic conditions met during the cruises, in the form of a histogram of winds and of temperature and moisture vertical differences between the sea surface and the ship meteorological instruments.

\section{a. SOFIA/ASTEX}

The Surface de l'Océan, Flux et Interactions avec l'Atmosphère experiment (SOFIA), as part of the Atlantic Stratocumulus Transition Experiment (ASTEX; Albrecht et al. 1995) was our first experiment (Weill et al. 1995). It was carried out in cooperation with P. K. Taylor's group at the Southampton Oceanography Centre (SOC; Yelland et al. 1994) and K. Katsaros's group at the University of Washington who already had experience in flux measurements (Katsaros et al. 1993). This campaign gave us the opportunity to test a set of instruments on board a ship, and to perform the first determinations of fluxes using the ID method. However, 

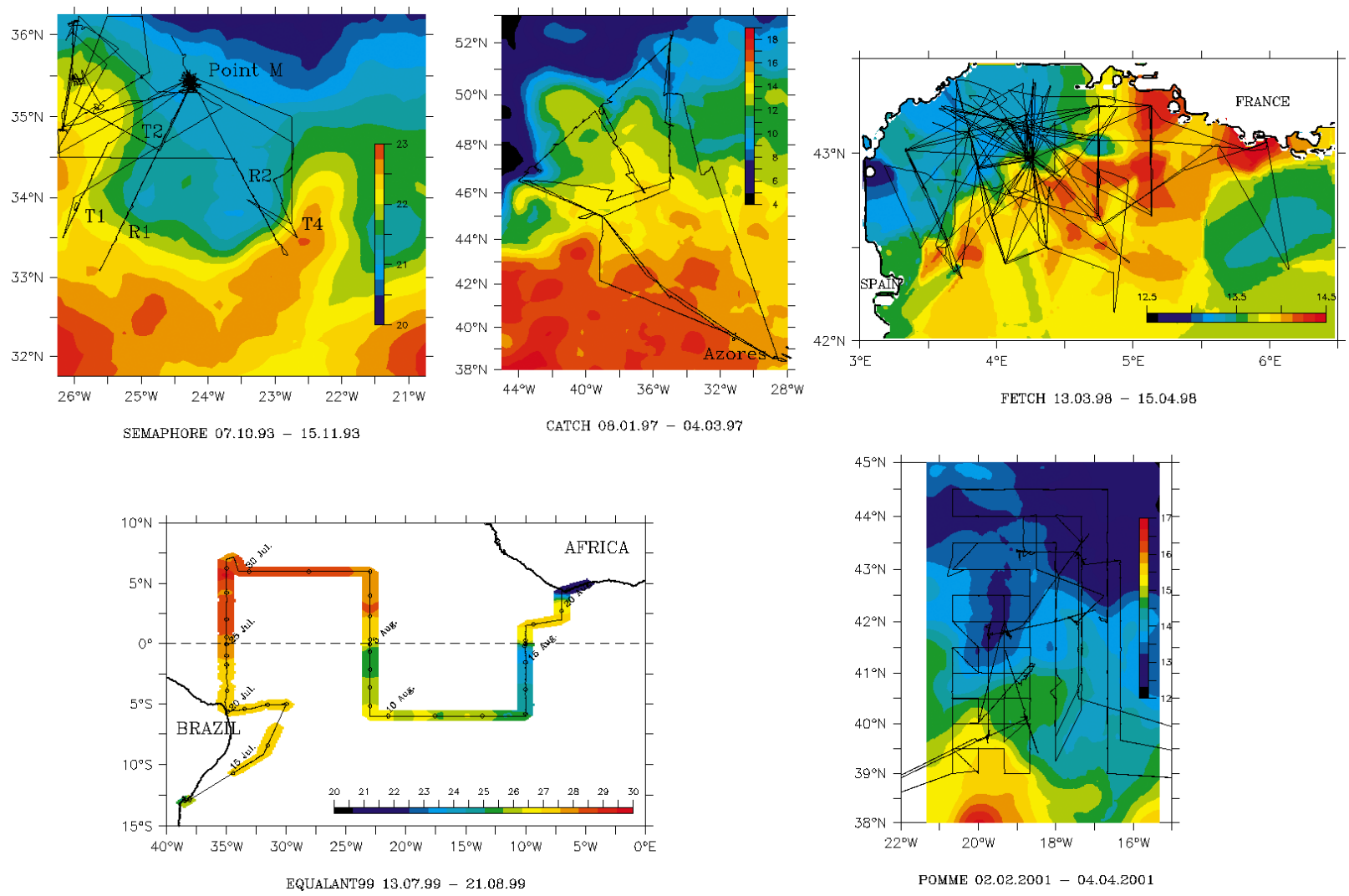

FIG. 1. Location of the different experiments and ship trajectories superimposed on SST maps derived from objective analysis.

data from this experiment are not yet included in the ALBATROS database due to the turbulence data acquisition and processing by several teams, but mean meteorological measurements and fluxes are included in the National Aeronautics and Space Administration (NASA) ASTEX database. Finally, this experiment can thus be considered a test experiment rather than an operational scientific cruise.

\section{b. SEMAPHORE}

The Structure des Echanges Mer-Atmosphère, Propriétés des Hétérogénéités Océaniques: Recherche Expérimentale (SEMAPHORE) experiment was specifically devoted to the measurement of air-sea fluxes, with a large component dedicated to mesoscale flux heterogeneities (Eymard et al. 1996) mainly in relation to an oceanic front in the experimental zone with an associated SST gradient (the Azores front; see Fig. 1). The instrumentation used on board R/V Le Suroît was derived from SOFIA/ASTEX and allowed the measurement of fluxes by the ID method. A first bulk parameterization was proposed for turbulent fluxes. Ship turbulent flux measurements were also compared with those measured by two planes (Durand et al. 1998). Oceanic measurements from ships and buoys made it possible to evaluate the surface heat budget and, thus, to evaluate fluxes to larger scales (Caniaux and Planton 1998) and to initiate work involving the effect of the SST heterogeneity on the atmospheric boundary layer (see section 6). A special section in the Journal of Geophysical Research (1998, vol. 103, no. C11) was devoted to this experiment (Eymard 1998 and papers therein).

\section{c. $\mathrm{CATCH}$}

Due to its location in the Newfoundland Basin and to the concerned period (winter 1997; Table 1), the Couplage avec l'Atmosphère en Conditions Hivernales $(\mathrm{CATCH})$ experiment, which is part of the Front and Atlantic Storm Track Experiment (FASTEX; Joly et al. 1999) was an opportunity to evaluate fluxes under strong winds and large stable and unstable stratifications (Eymard et al. 1999). This dataset is certainly a major contribution to the ALBATROS database due to the various atmospheric and oceanic conditions sampled in this area. Moreover, a number of technical improvements in instrumentation were tested during this campaign, taking into account the experiences drawn from SEMAPHORE. In addition, the U.S. R/V Knorr was present in the experiment area for two weeks and made simultaneous flux measurement with the R/V Le Suroit (Hare et al. 1999). In addition, the strong sea surface tem- 

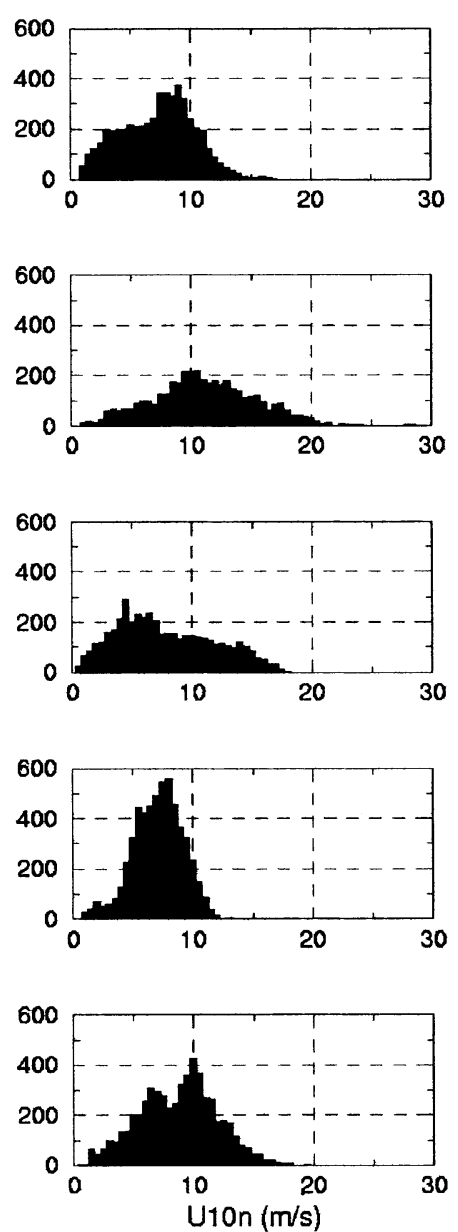

\section{SEMAPHORE}
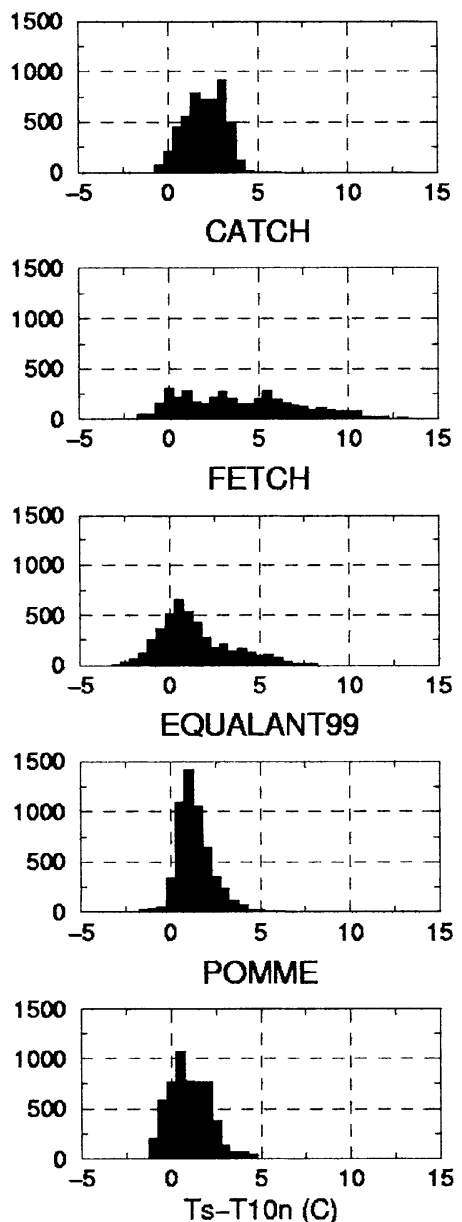
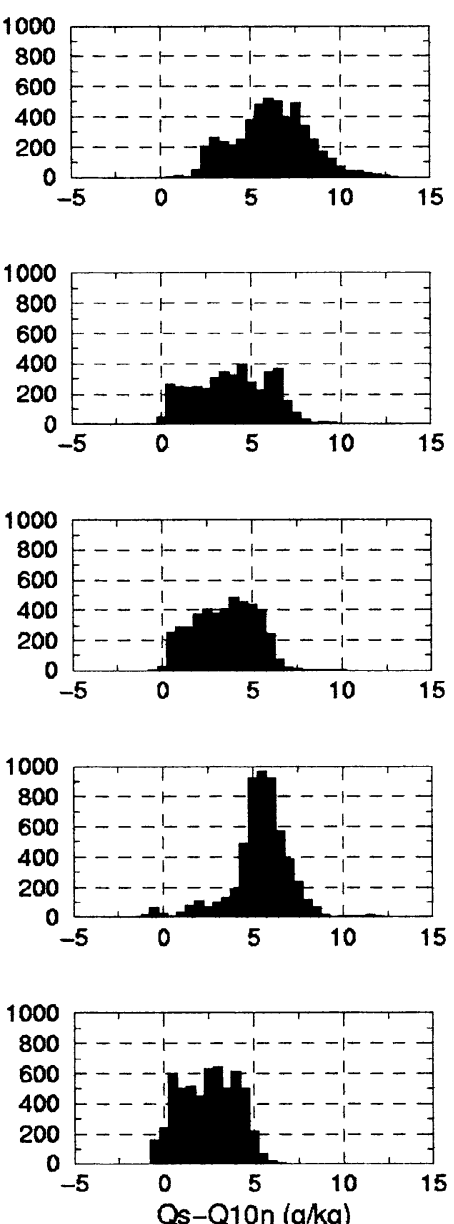

FIG. 2. Histograms of (left) wind, (middle) temperature difference, and (right) specific humidity difference deduced from data collected during (first row) SEMAPHORE, (second row) CATCH, (third row) FETCH, (fourth row) EQUALANT99, and (last row) POMME experiments. Temperature in ${ }^{\circ} \mathrm{C}$ (specific humidity in $\mathrm{g} \mathrm{kg}^{-1}$ ) differences have been computed as SST minus temperature at 10-m height and in neutral stratification; winds in $\mathrm{m} \mathrm{s}^{-1}$ were also reduced at $10-\mathrm{m}$ height and in neutral stratification.

perature (SST) gradient associated with the North Atlantic and Labrador Current transition (Caniaux et al. 2001) allowed further study of the turbulent flux variations across such structure, and to check the consistency of model and satellite fluxes (see section 6).

\section{d. FETCH}

The Flux, Etat de la Mer et Télédétection en Condition de Fetch Variable (FETCH) experiment was devoted to the study of turbulent fluxes in relation to sea state variation (Hauser et al. 2000). It was the only experiment carried out in a coastal condition to tackle the problems of flux heterogeneity from shore to open sea. For this experiment, ID and ECM were compared with results from a moored buoy [the Air-Sea Interaction Spar (ASIS) buoy; Graber et al. 2000]. From these results we got precise information that the winds measured on top of the mast were affected by the deformation of the airflow. Corrections were obtained from specific simulations (see section 4). A special issue soon to appear in the Journal of Geophysical Research (Hauser et al. 2002) is dedicated to the main results obtained during this experiment.

\section{e. EQUALANT99}

For the equatorial Atlantic 1999 (EQUALANT99) experiment, the configuration of the measurement system was similar to that of FETCH, due to the quality of the dataset obtained and the reliability of the acquisition system. However, the use of another ship (R/V La Thalassa) led us to make new physical and numerical simulations for correcting winds. This experiment, mainly dedicated to the oceanic circulation in the tropical Atlantic basin (Gouriou et al. 2001), was also devoted to surface fluxes for obtaining a bulk flux parameterization adapted to the mooring network in this region [the Pilot Research Moored Array in the Tropical Atlantic (PIR- 
ATA) program; Servain et al. 1998]. Analysis of this experiment is still in progress.

\section{f. POMME}

The Programme Océanique Multidisciplinaire à Méso-Echelle (POMME) program was a large research program aimed specifically at the study of the subduction mechanisms of the northeastern Atlantic mode water and their effects on the biogeochemical cycles. Hence, surface fluxes were central to the scientific objectives of this program. The interest of this campaign was its length $(1 \mathrm{yr})$, during which turbulence data were collected continuously for the 4 months of intense observing periods (experiments POMME1 and POMME2, from February to May 2001). A large variety of oceanic-atmospheric situations were sampled and will be a major contribution for ALBATROS. Again, data analysis is still in progress. In addition, the deployment of an anchored buoy, many drifters and floats, and the availability of satellite data and model fluxes will be used to determine high horizontal resolution heat and momentum surface fluxes within the experimental zone and during an annual cycle.

\section{Instrumentation}

In this section we describe the main instruments used to get fluxes during the successive campaigns. Improvements and instrumental modifications from one experiment to the other are indicated in bold in Table 2 . During SOFIA, our first "test experiment," we used the 10-m SOC mast with a sonic anemometer at the top (Yelland et al. 1994) and the Lyman-alpha humidity sensor from the University of Washington (Katsaros et al. 1993). Other instruments and complementary information aboard the ships are indicated in Table 1 .

For all the campaigns (except SOFIA), the meteorological package, which includes instruments for mean and turbulent parameters, was implemented at the top of the mast (about $17 \mathrm{~m}$ above the surface), located on the foredeck of the different ships used. The incoming and longwave radiation were also systematically measured with instruments mounted with a hook's coupling system. A net radiation sensor was installed on a 6-8-mlong boom at the bow of the ship (in moderate sea state conditions). The SST and salinity were measured at depths ranging between 2 and $4 \mathrm{~m}$ depending on the ship. All the mean measurements were sampled at 10 $\mathrm{s}$, then averaged over $1 \mathrm{~min}$, before being stored in daily files in the ALBATROS database.

For turbulence, a sonic anemometer was systematically used (with a new system for FETCH and the following campaigns in which the axis is horizontal instead of vertical). Due to salt deposit in the Lyman-alpha hygrometer, a microwave refractometer, previously tested on board an aircraft, has been tentatively used since CATCH in 1997. After checking that the refractive in- dex fluctuation spectrum exhibits an inertial subrange, the combination with the temperature derived from the sonic speed makes it possible to get humidity fluxes; observations and simulations proved that salt deposit and spray had negligible effect (Delahaye et al. 2001; Eymard et al. 1999).

In addition to previous sensors, a motion package has been used since CATCH to test the implementation of the eddy-correlation method on large ships. Unfortunately only three degrees of freedom (two angles and one acceleration) could be recorded with this system instead of six degrees of freedom required for optimal motion correction. However during FETCH we analyzed the effect of this limitation on ECM through a comparison with the ASIS buoy motion package on board the ship. During the last experiment (POMME), a relaxed-eddy accumulator system was implemented on the ship and coupled with the equipment of the mast, in order to measure trace gas components, and specially to get humidity and $\mathrm{CO}_{2}$ fluxes. In a first step, this system is being evaluated by comparing evaporation fluxes with the ID and ECM fluxes (Brut et al. 2002b).

\section{Flow distortion correction}

Effects of flow distortion over the platforms has been pointed out (Blanc 1986, 1987; Yelland et al. 1998) as a possible source of differences between flux estimates from one platform to the other in similar experimental conditions. To take this possible effect into account, disturbances of the airstream caused by the ship and its hull, the decks, and the instrumented mast are simulated in three dimensions. Yelland et al. (2002) used computational fluid dynamics (CFD) simulations to analyze the airflow distortion over several research vessels. They demonstrated the importance of the sensor location on the distortion effect, as well as the increased distortion in case of transverse and astern wind.

Two facilities are available at the French meteorological office (Météo-France): a water channel for physical simulations of the atmosphere and CFD software that is generally used for numerical simulations of disturbances around aircraft and airborne instruments. The opportunity was thus presented to use and evaluate both methods, and, in particular, to explore the respective influence of the mast and ship structure on the airflow distortion. Ship models can be very detailed, so the instrumented lattice mast could be built with fine details and mounted on a complete ship hull. Effects of roll and pitch angles are easy to test (static simulation). The CFD computation was performed for the $\mathrm{R} / \mathrm{V}$ L'Atalante. The ship was paneled and put in a virtual wind tunnel. Even if the numerical simulations take advantage of the increasing speed of computers, they are still limited, for the details of the meshed ship hull, by the computing time.

To take advantage of the capabilities of both methods, simulations were performed complementary to each oth- 


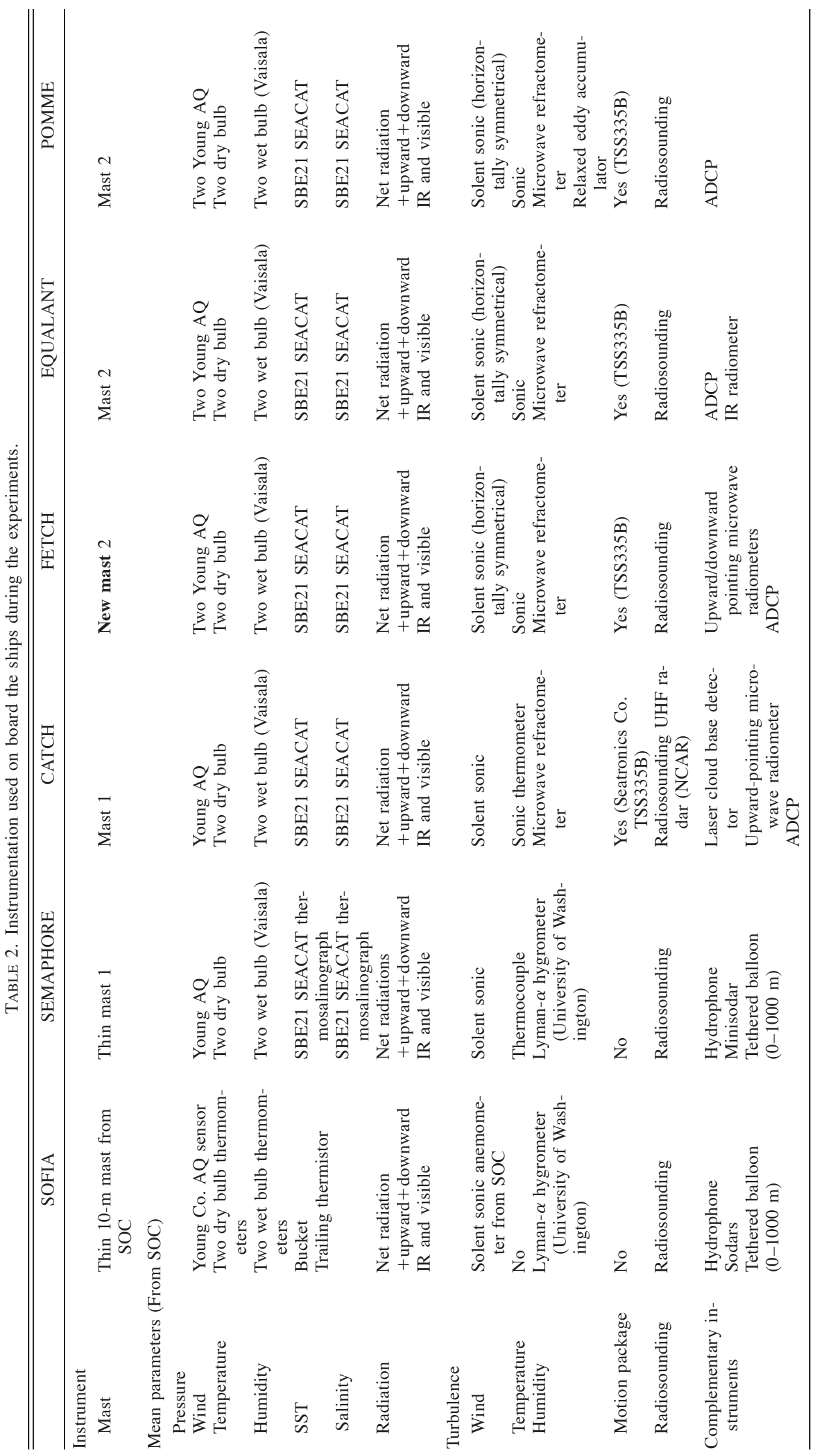


er: after validation with respect to sonic anemometer measurements, specific simulations will be discussed concerning the respective effects of the ship and the instrumented mast, and the impact of pitch and roll. Results obtained for $\mathrm{R} / \mathrm{V}$ L'Atalante will be shown in this section.

\section{a. The simulation methods}

\section{1) Physical Simulations}

The distortion was studied on models of the R/V Thalassa and R/V L'Atalante at the 1/60 scale in a water flow (Perrier and Butet 1988) in a large channel (length: $30 \mathrm{~m}$, width: $3 \mathrm{~m}$, height: $1.6 \mathrm{~m}$ ). A standard marine boundary layer with a $10 \mathrm{~m} \mathrm{~s}^{-1}$ upstream velocity was simulated. Due to the similarity, the simulations apply for wind speed ranging from 5 to $30 \mathrm{~m} \mathrm{~s}^{-1}$ for scaled parameters such as the horizontal wind speed errors and slope angles defined below. Velocity measurements were performed along a vertical profile below and above the sonic anemometer location. The horizontal and vertical components of the flow speed are measured with a laser anemometer. The accuracy of this nonintrusive technique is up to $2 \%$. Some visualizations are performed by means of laser sheets to get the flow pattern close to the mast and near the ship bow (Butet 2002).

Several experimental conditions are used to characterize the flow distortion: five inlet azimuth angles $\left(-30^{\circ},-15^{\circ}, 0^{\circ}, 15^{\circ}\right.$, and $\left.30^{\circ}\right)$; five pitch angles $\left(-10^{\circ}\right.$, $-5^{\circ}, 0^{\circ}, 5^{\circ}$, and $\left.10^{\circ}\right)$; and three roll angles $\left(0^{\circ}, 5^{\circ}\right.$, and $\left.10^{\circ}\right)$. Specific simulations were performed on R/V Thalassa with and without the mast.

\section{2) Numerical SIMULATIONS}

The CFD model (commercially available from Fluent Inc.) deals with a finite volume suited for incompressible and compressible fluid flow in complex three-dimensional geometry. It includes several turbulence parameterizations as the standard $k-\varepsilon$ or the large eddy simulation. This code was used to simulate the flow distortion induced by the $\mathrm{R} / \mathrm{V}$ L'Atalante and the mast at the sonic anemometer location. The ship was paneled and enclosed in a rectangular volume $(200 \mathrm{~m} \times 60 \mathrm{~m}$ $\times 60 \mathrm{~m}$ ) simulating a wind tunnel. The panels were generated as an unstructured mesh of triangular cells, allowing the model to have a fine resolution near the sea surface and the ship body. However, it was not possible to represent the fine structure of the lattice mast, which was consequently meshed as a full body. In a second step, the fine structure of the mast was meshed, but without the ship, and turbulent simulations were performed to show the small-scale distortion around sensors.

Most of the simulations were run in laminar flow conditions to investigate the mean properties of the flow. However, for both laminar and turbulent, flow condi- tions show very similar results at the sensor locations (ship distortion effect). The upstream wind direction and velocity were specified with four different inlet velocities $\left(5,10,15\right.$, and $\left.20 \mathrm{~m} \mathrm{~s}^{-1}\right)$ and six different inlet azimuth angles $\left(0^{\circ}, 20^{\circ}, 50^{\circ}, 90^{\circ}, 150^{\circ}\right.$, and $180^{\circ}$ with respect to the ship orientation). As the mast is located on the centerline of the foredeck, negative angles were not simulated. The slight asymmetry of the ship superstructure was therefore neglected. An illustration of the airflow distortion effect is given in Fig. 3, which shows the velocity vectors on the hull, the mast, and the sea surface for $15 \mathrm{~m} \mathrm{~s}^{-1}$ and $50^{\circ}$ inlet flow.

\section{b. Results}

\section{1) VALIDATION OF AIRFLOW DISTORTION SIMULATIONS}

The sonic anemometer provides the three components of the wind. After correction for the ship motion using the motion package, the average vertical velocity was found to significantly differ from zero. Figure 4a represents the recorded vertical versus the horizontal velocity for the relative azimuth smaller than $100^{\circ}(\mathrm{R} / \mathrm{V}$ $L^{\prime}$ 'Atalante, FETCH experiment) for wind data averaged over $30 \mathrm{~min}$. A slope angle of about $7^{\circ}$ is observed on average. A similar result was obtained for R/V Thalassa during EQUALANT99. Figure $4 \mathrm{~b}$ shows the corresponding CFD-simulated velocity components for upstream winds ranging from 5 to $20 \mathrm{~m} \mathrm{~s}^{-1}$ and for azimuth angles between $0^{\circ}$ and $90^{\circ}$. The same mean angle of $7^{\circ}$ is obtained.

In Figure 5, the slope angle, defined as $\operatorname{atan}(W / U)$, where $W$ and $U$ are, respectively, the mean vertical and horizontal component of the wind speed, is plotted as a function of the wind azimuth. Figure 5a displays the observations, and CFD simulations are shown in Fig. $5 \mathrm{~b}$. Similar to the measurements, the slope angle is nearly constant up to $120^{\circ}-130^{\circ}$, then becomes negative, reaching $-7^{\circ}$ for an astern wind ( $180^{\circ}$ azimuth). Physical simulations lead to similar results (not shown): a $6^{\circ}$ slope angle is found at the location of the sonic anemometer, with a slight variation (between $5.5^{\circ}$ and $6.5^{\circ}$ ) for azimuth within the $\left[-30^{\circ},+30^{\circ}\right]$ interval. At $180^{\circ}$ azimuth, a $-7.5^{\circ}$ angle is observed. The agreement with observations and CFD results is therefore satisfactory, considering the scatter in the measurements (Figs. 4a and 5a).

\section{2) RESUlts ON THE HORIZONTAL WIND VELOCITY} AND EFFECTS OF THE MAST ON AIRFLOW DISTORTION

The observed vertical component is generated because of the change in the pressure field above the ship deck. It corresponds to a decrease or an increase of the horizontal wind, depending on the azimuth.

On R/V Thalassa, a test was performed using physical 


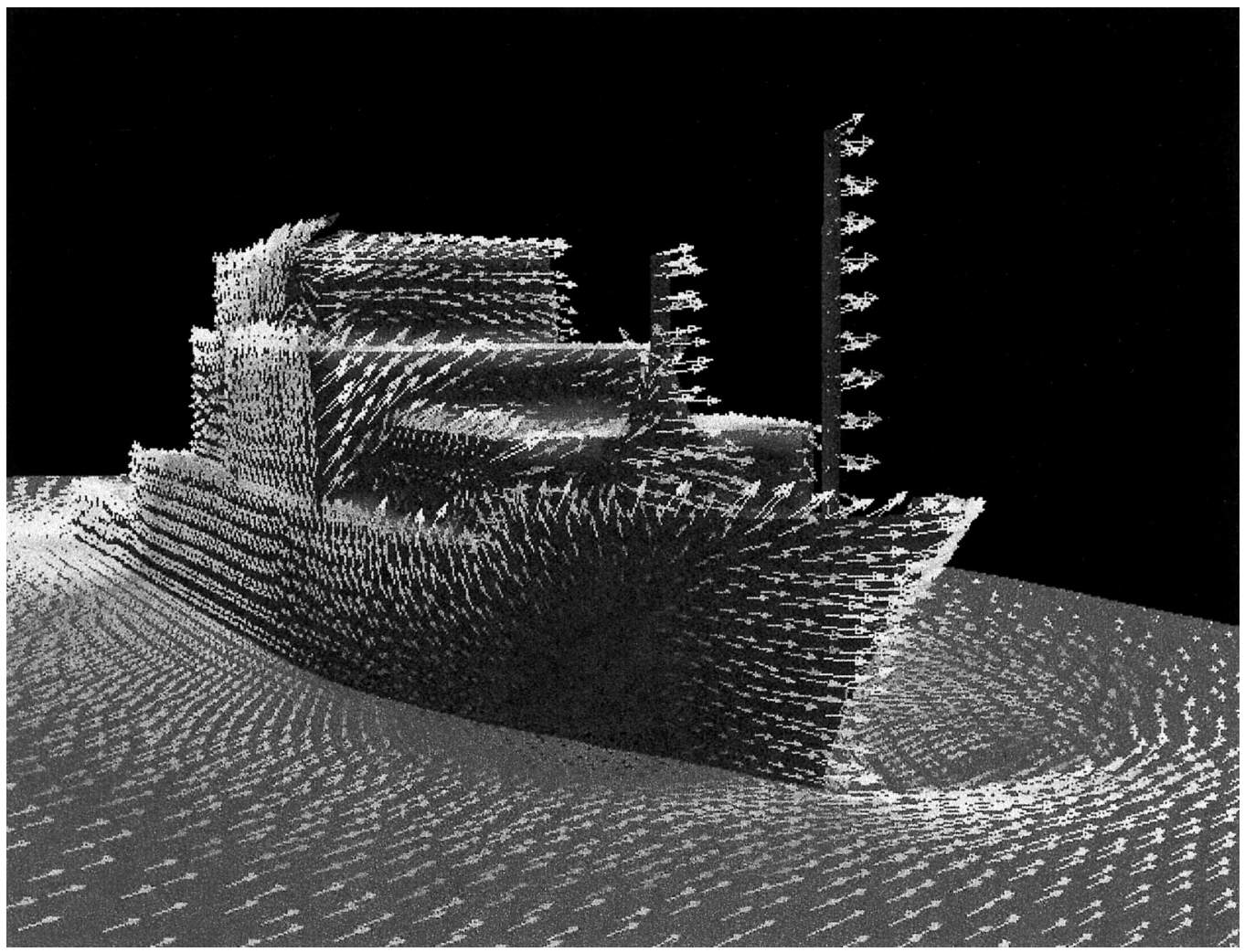

FIG. 3. Display of the computed velocity vectors around the R/V L'Atalante, for an incoming wind of $15 \mathrm{~m} \mathrm{~s}^{-1}$ and an azimuth angle of $50^{\circ}$.

simulation to quantify the effect of the mast with respect to the ship: the aerodynamic envelope of the ship induces a wind speed decrease up to $2 \%$ above the deck $\left(0^{\circ}\right.$ azimuth $)$. The mast amplifies this perturbation, which reaches $10 \%$ at the location of the sonic anemometer. Note that CFD simulations on R/V L'Atalante without the mast confirm this result (5\% decrease instead of $10 \%$ ).

Profiles of the relative horizontal velocity (ratio of the observed wind at the vertical of the sensor location to the unperturbed upstream wind) obtained from the water channel are plotted in Fig. 6 for azimuth angles between $-30^{\circ}$ and $30^{\circ}$ (R/V L'Atalante). They show that the perturbation is located near the top of the mast (maximum at about $0.5 \mathrm{~m}$ below the anemometer). At the sonic anemometer location (horizontal dotted line), the relative velocity ranges between $0.93\left(0^{\circ}\right.$ azimuth $)$ and $1\left(+30^{\circ}\right)$. Because of the asymmetry of the ship, slightly different results are obtained for positive and negative angles. The CFD simulation with the full mast for $0^{\circ}$ azimuth (superimposed dashed line in Figs. 6) leads to a similar result at the sonic anemometer position, as the relative velocity is 0.95 .

Above the sensor, the perturbation rapidly decreases, being $1 \%$ or less $1 \mathrm{~m}$ above it, from both CFD and physical simulations. However, the two simulations strongly differ below the sonic anemometer: the CFD relative speed reaches 0.65 , whereas it becomes too close to unity for physical simulations. To explain this result, a CFD simulation of the mast alone (complete lattice mast with the three uprights, the rungs across them, and the electronic boxes) was performed for a 10 $\mathrm{m} \mathrm{s}^{-1}$ inlet wind (solid line in Fig. 6): the maximal distortion is obtained at the same height as for physical simulation, and decreases below. A smaller perturbation is obtained ( 0.97 instead of 0.93 at the sonic height) because the ship was not included in the simulation, but the profile is qualitatively similar. Hence, the perturbation is mainly due to the presence of electronic boxes fixed on top of the mast and located near the anemometer. These containers induce an aerodynamic break point and force a strong perturbation at this level. Thus, the full mast used in CFD gives consistent results at the sensor location and above but not below.

Another consequence of flow distortion is that the actual measurement height corresponds to an upstream wind at a different height, as also stressed by Yelland et al. (2002). Due to the presence of the ship, the flow is vertically elevated at bow angles. To evaluate this height shift, path lines were calculated to visualize the flow of massless particles and reversed to follow these particles back to their source. The estimated height shift is $\Delta z=-1.2 \mathrm{~m}$ for a $10 \mathrm{~m} \mathrm{~s}^{-1}$ wind facing the ship 

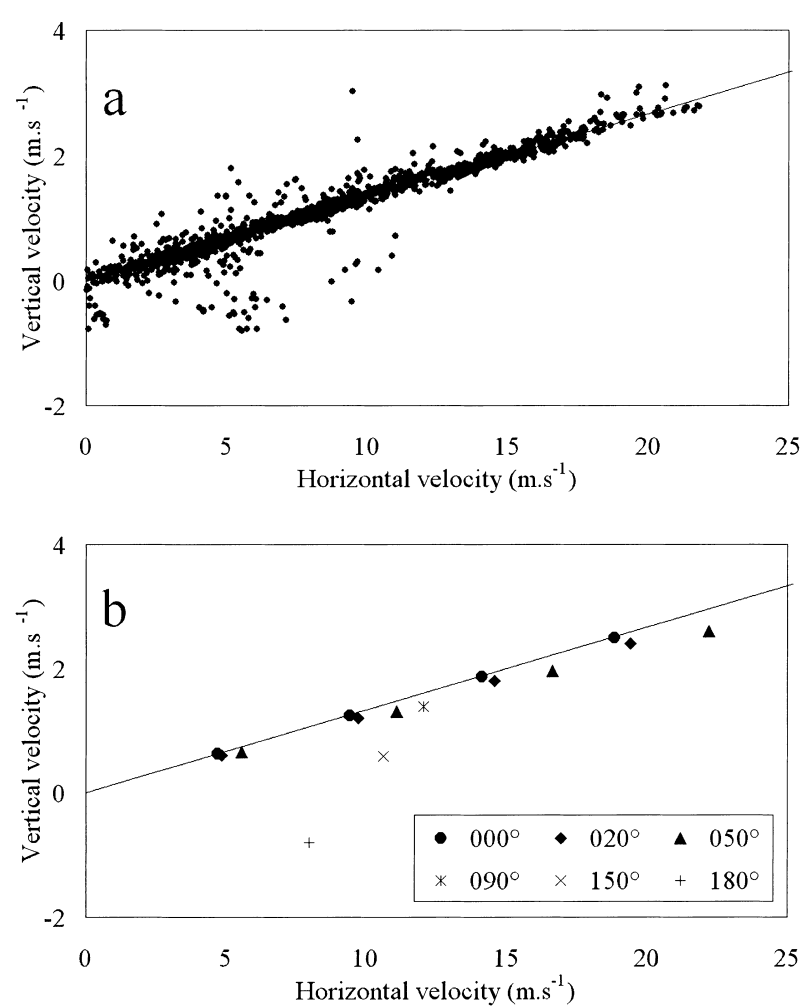

FIG. 4. Vertical component $\left(\mathrm{m} \mathrm{s}^{-1}\right)$ of the wind plotted against its horizontal component $\left(\mathrm{m} \mathrm{s}^{-1}\right)$. (a) Measurements from the sonic anemometer on R/V L'Atalante during FETCH; (b) CFD simulation for various azimuth angles $\left(0^{\circ}, 20^{\circ}, 50^{\circ}, 90^{\circ}, 150^{\circ}\right.$, and $\left.180^{\circ}\right)$, with respective symbols given at bottom right.

(azimuth $0^{\circ}$ ). From flow visualization in the water channel, the height shift was estimated to $-1.1 \mathrm{~m}$.

Finally, the direction of the horizontal wind is also modified by distortion, the apparent wind being deviated by up to $10^{\circ}$ compared to the upstream wind azimuth (in average, from CFD simulations).

\section{3) IMPACT OF PITCH AND ROLL ON THE FLOW DISTORTION}

Physical simulations can also be easily used to evaluate the impact of pitch and roll on the distortion (static simulations). Pitch angles ranging between $-10^{\circ}$ and $10^{\circ}$, and roll angles of $5^{\circ}$ and $10^{\circ}$ were successively applied to the ship models in the water tank for a $10 \mathrm{~m}$ $\mathrm{s}^{-1}$ wind speed. The pitch was found to be important, resulting in variations of the slope angle by more than $1^{\circ}$, and up to $12 \%$ on the wind velocity for a $-10^{\circ}$ pitch (the ship bow leaning forward; Butet 2001, 2002). Moreover, these simulations demonstrate that the average value for two symmetrical pitches is not equal to the value for $0^{\circ}$ pitch. The distortion appears much less sensitive to the roll angle (evaluated for $5^{\circ}$ and $10^{\circ}$ roll angles), with less than $1 \%$ effect on the wind velocity.
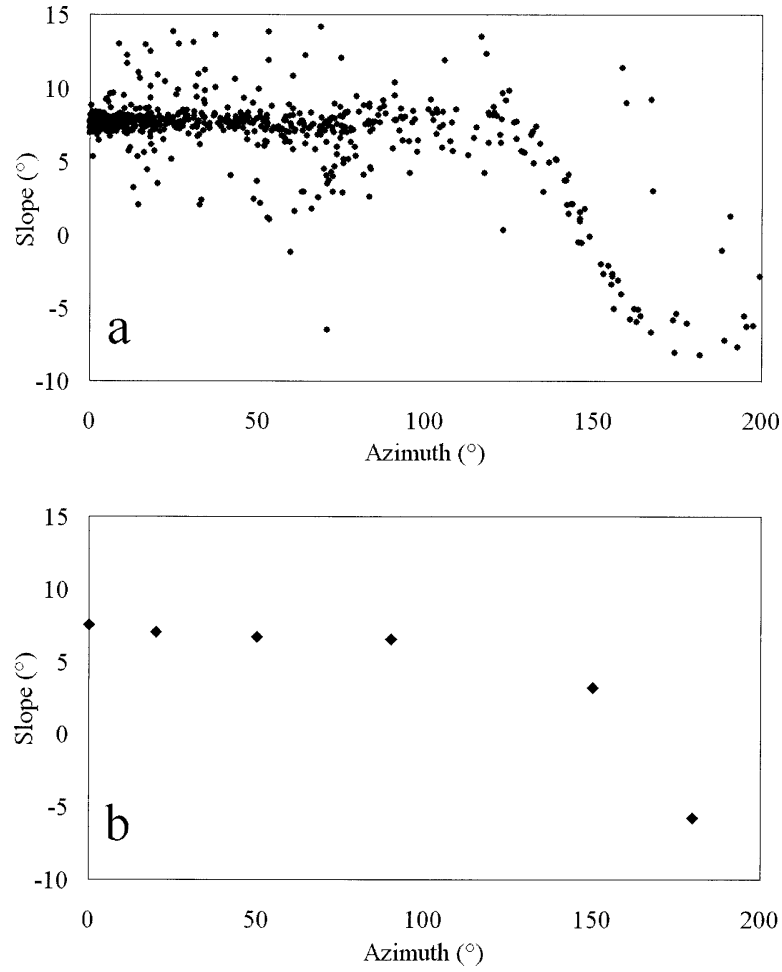

FIG. 5. Slope angle of the wind plotted against its azimuth angle on R/V L'Atalante during FETCH: (a) measurements; (b) simulations for a $10 \mathrm{~m} \mathrm{~s}^{-1}$ wind speed.

\section{4) Airflow Distortion CORRECTION}

Both physical and CFD simulations were found to agree with observations of airflow distortion. Similar results were obtained for R/V Thalassa and L'Atalante, but the different ship size and structures require specific simulation to get an accurate estimate of the airflow distortion. Polynomial fits were derived from their re-

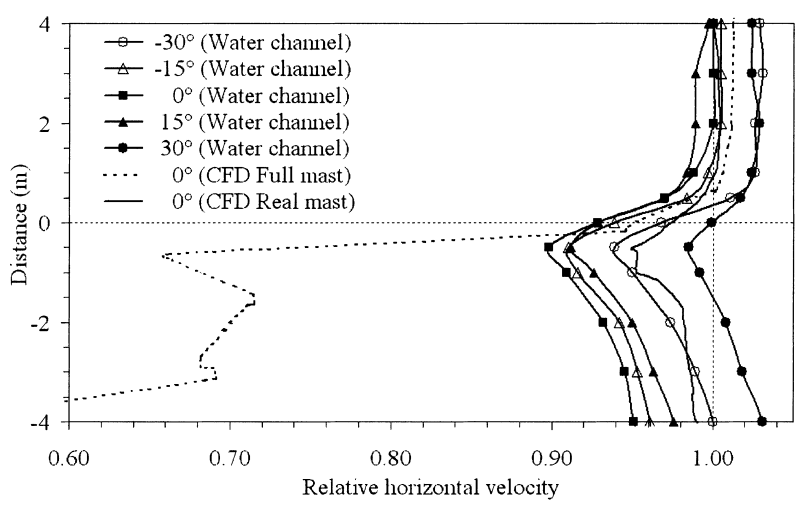

FIG. 6. Vertical profiles of the relative velocity (ratio of the apparent wind to the upstream velocity) for a $10 \mathrm{~m} \mathrm{~s}^{-1}$ upstream wind speed over R/V L'Atalante. Results at the sonic anemometer height are those for $z=0 \mathrm{~m}$. Physical simulations are shown for different azimuth angles $\left(0^{\circ}, 15^{\circ}, 30^{\circ}\right)$. CFD computations are superimposed (azimuth $0^{\circ}$ ): the dashed line is for the ship with a full mast; the solid line shows the effect of the real mast, but taken alone. 
TABLE 3. Turbulent flux estimates during each experiment. ID: inertial dissipation, ECM: eddy correlation method.

\begin{tabular}{lllll}
\hline \hline & ID & ECM & Heat flux & Airflow distortion \\
\hline SOFIA and SEMAPHORE & Yes & No & Lyman-alpha hygrometer & Not yet \\
CATCH & Yes & Not yet & Sonic temperature and refractometer & Not yet \\
FETCH & Yes & Yes & Temperature and refractometer & Yes \\
EQUALANT & Yes & Yes & Temperature and refractometer & Yes \\
POMME & In progress & & Temperature and refractometer & Yes (FETCH correction) \\
\hline
\end{tabular}

sults to correct the horizontal and vertical wind components. They were used for processing the FETCH, EQUALANT99, and POMME data. In the following, we use a correction derived from CFD for L'Atalante (Dupuis et al. 2002), and one derived from physical simulations for La Thalassa (Brut et al. 2002a). Note that the above results were assessed for medium to high winds, but not for low wind conditions (below $5 \mathrm{~m} \mathrm{~s}^{-1}$ ).

Further simulations are needed for the R/V Le Suroît used during SOFIA, SEMAPHORE, and CATCH. The major difference between these first experiments and the latter three is that the sonic anemometer was pointing vertically above the mast. CFD simulations of the mast showed that the distortion rapidly cancels above the mast, leading to a null perturbation at $0.75 \mathrm{~m}$ (the height of the CATCH sonic anemometer). Moat and Yelland (1996) performed a CFD simulation of R/V Le Suroît with a thin mast inducing very small distortion at low azimuth angles. As a first approximation, we took advantage of their simulations for estimating the airflow distortion during CATCH for facing winds (M. J. Yelland 2001, personal communication) by using a vertical displacement of $0.68 \mathrm{~m}$ and a wind speed error of $0.7 \%$.

Finally an open issue remains as to whether it is suitable or not to apply these corrections to turbulent data since both numerical and physical simulations do not provide results at very small scales: turbulent eddies can develop around the ship superstructures and give rise to bias in the turbulent flux estimates, mainly with the ECM.

\section{Flux parameterization}

\section{a. Methods}

Extensive field experiments provide estimates of turbulent fluxes that can be used to derive bulk formulas, based on the drag and heat or evaporation transfer coefficients $C_{\mathrm{DN}}, C_{\mathrm{HN}}$, and $C_{\mathrm{EN}}$, as follows:

$$
\begin{aligned}
& \langle u w\rangle=C_{\mathrm{DN}} U_{10 \mathrm{~N}}^{2} \\
& \langle w q\rangle=C_{\mathrm{EN}} U_{10 \mathrm{~N}}\left(Q_{\mathrm{sat}}-Q_{10 \mathrm{~N}}\right) \\
& \langle w t\rangle=C_{\mathrm{HN}} U_{10 \mathrm{~N}}\left(\mathrm{SST}-T_{10 \mathrm{~N}}\right),
\end{aligned}
$$

where $U, T, Q, \mathrm{SST}$, and $Q_{\text {sat }}$ stand, respectively, for mean wind speed, air temperature, humidity, sea surface temperature, and humidity at saturation. Subscript " $10 \mathrm{~N}$ " stands for equivalent neutral parameters at 10 $\mathrm{m}$. The ocean surface current is generally neglected in bulk formulas unless significant currents are observed, as noted in Eq. (1).

Fluxes are estimated by the inertial-dissipation method and the direct covariance or eddy-correlation method. The first one is based on the measurements of dissipation rates derived from the energy of the fluctuations in the inertial subrange (typically at frequencies higher than 1 $\mathrm{Hz}$ ). Then fluxes are estimated using the turbulent kinetic energy (TKE) budget and the variance budget, respectively, for momentum and heat fluxes. The different production terms of these equations are parameterized following the Monin-Obukhov similarity theory, while the sum of vertical transport terms (turbulent and pressure transport) is usually considered as being negligible compared to production and dissipation terms. The second method consists in obtaining the covariance of fluctuations of the vertical wind velocity component and a parameter of interest (longitudinal wind velocity component, air potential temperature, and specific humidity providing, respectively, momentum, sensible, and latent heat flux). This last method is the most reliable mean for estimating turbulent fluxes, as it is a direct method, but its use remains complicated aboard research vessels. The major difficulty lies in the fact that the observed wind velocity must be corrected from ship motions. Derivation of eddy-correlation fluxes is based on equations described in Anctil et al. (1994), but with approximate horizontal accelerations because the motion package only provides two angles (pitch, roll) and the vertical acceleration (heave) (Pedreros et al. 2002, manuscript submitted to J. Geophys. Res., hereafter PED). Contrary to ID, the latter method integrates all turbulence scales and can be affected by turbulent eddies due to airflow distortion.

Table 3 summarizes how fluxes were estimated during the campaigns and the status of airflow distortion correction availability, from CFD and physical simulation, as discussed in section 4 . In the following, we use the simple estimate provided by Yelland et al. (2002) for R/V Suroît during CATCH.

\section{b. Status of the flux parameterization development}

Several papers have been published to present the results obtained for each field campaign. They can be summarized as follows:

- For the SOFIA and SEMAPHORE campaigns, moderate wind speeds and unstable stratifications were 
encountered. This dataset showed that the ID estimates of the drag coefficient, $C_{\mathrm{DN}}$, were much lower for unstable stratifications than for neutral conditions. This led us to introduce the stability-dependent vertical transport term in the TKE budget (Dupuis et al. 1997).

- First results for CATCH and FETCH (without airflow distortion correction) were found to exhibit much higher $C_{\mathrm{DN}}$ values at high wind speeds than generally obtained in the literature (Eymard et al. 1999; Dupuis et al. 1999). These surprising results caused us to start a program of airflow simulations.

- First physical and numerical simulations of mean airflow distortions for FETCH and EQUALANT99 vessel/mast/sensor configurations showed that correcting for the mean airflow distortion allows us to provide $C_{\mathrm{DN}}$ by ID in agreement with other studies based on buoys, thus minimizing the airflow distortions (Dupuis et al. 2002).

- Further corrections for airflow distortion were developed to account for pitch and roll effects in case of R/V Thalassa for EQUALANT99 (Brut et al. 2002a).

- Momentum flux by ECM are in contrast biased up by $15 \%$ with respect to ID values. This was interpreted to be due to turbulent airflow distortion not yet accounted for (PED) in agreement with Edson et al. (1998).

- This turbulent airflow distortion component does not, however significantly affect ECM heat fluxes even on large vessels: sensible heat fluxes obtained during FETCH on R/V L'Atalante and on the ASIS buoy (negligible airflow distortion) compare very well (PED).

- The refractometer is a very powerful sensor for providing fluctuations of air refraction index. This index depends to first order on air humidity and second order on air temperature (Delahaye et al. 2001; Dupuis et al. 1999), and allows us to calculate the latent heat flux.

- The sonic temperature as provided by sonic anemometers is a promising technique for fluctuations at low and medium frequencies (i.e., to be used for ECM) but not so accurate for high frequencies (i.e., to be used for ID; Dupuis et al. 2002; PED; Brut et al. 2002a).

\section{c. ALBATROS project and ongoing analyses}

The main objective of the ALBATROS project is to provide the software tools to process the turbulent flux, in addition to the database of experimental campaigns with extensive documentation (sensors, processing, format, etc.).

This objective is achieved for flux estimate by ID for most past experiments, including preliminary results from POMME. ECM fluxes will also be added in the database as soon as they are fully validated.
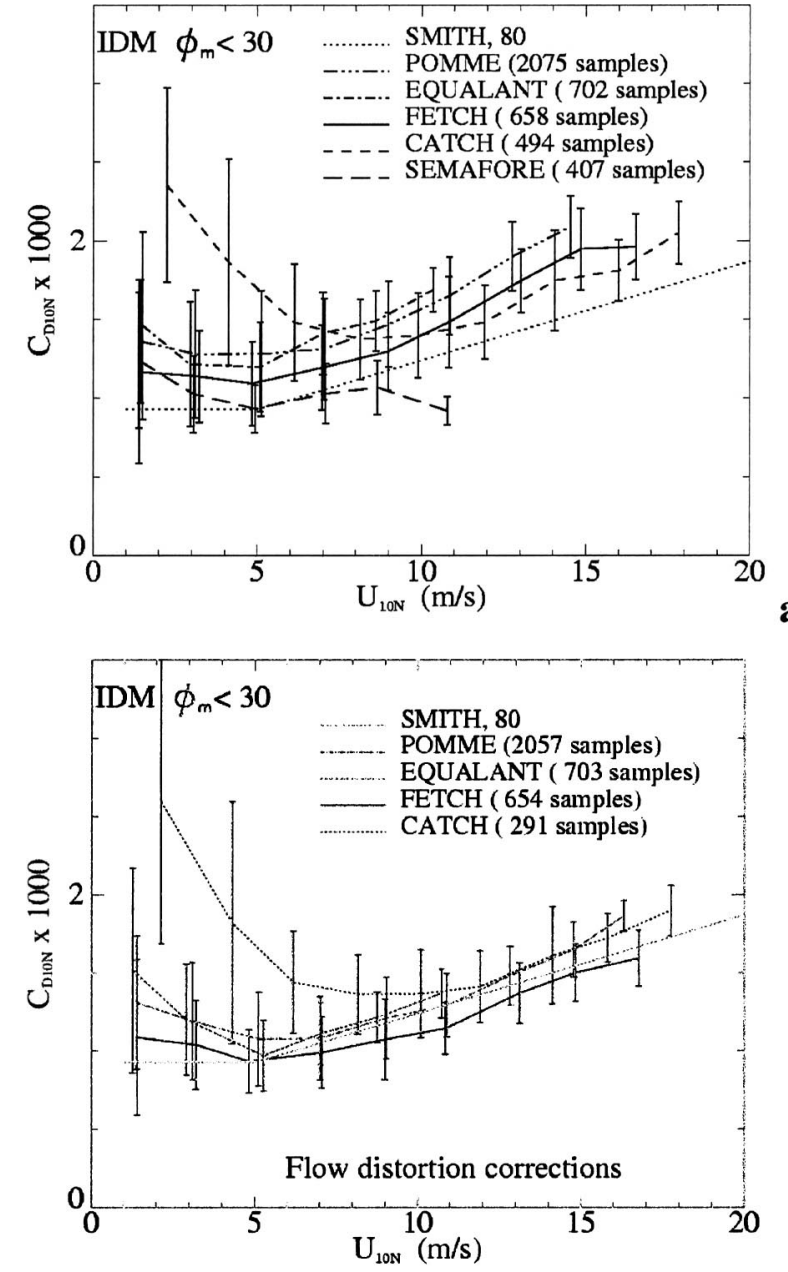

FIG. 7. Drag coefficients derived from ID for the various experiments. (a) Superposition of mean drag coefficients with the associated std dev in each $2 \mathrm{~m} \mathrm{~s}^{-1}$ bin. The Smith (1980) parameterization is also plotted (dotted line). (b) CATCH, FETCH, EQUALANT, and POMME mean drag coefficients after airflow distortion correction. Again the Smith parameterization is plotted.

Figure 7 shows the results for the drag coefficients as a function of wind speed (for both parameters reduced to 10 -m height and to neutral stratification), for all experiments using ID with exactly the same software, available in the ALBATROS base. In Fig. 7a, the mean values, calculated in each $2 \mathrm{~m} \mathrm{~s}^{-1}$ bin, are plotted, with the associated standard deviation. The five experiments exhibit an increase of $C_{\mathrm{DN}}$ for wind speed higher than about $7 \mathrm{~m} \mathrm{~s}^{-1}$ in the so-called rough aerodynamic domain, but with slightly different slopes and discrepancies in average values. After correcting data from all experiments but SEMAPHORE with the simple polynomial expressions mentioned in section 4 , the respective results do not significantly differ, and a good agreement with Smith's (1980) parameterization is observed (Fig. 7b).

Thus results provided by the ALBATROS database 


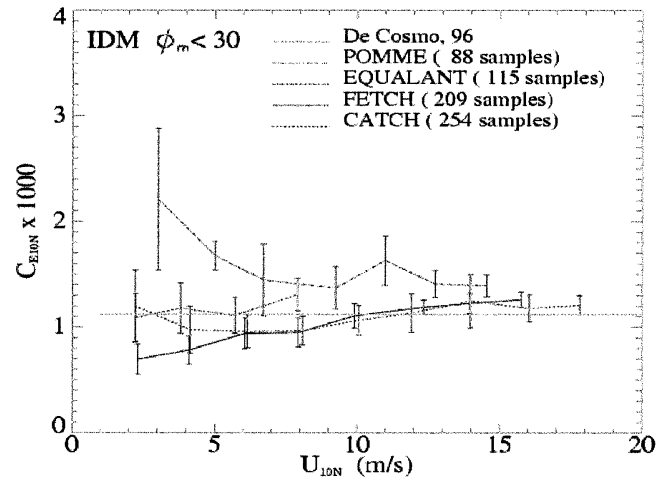

a

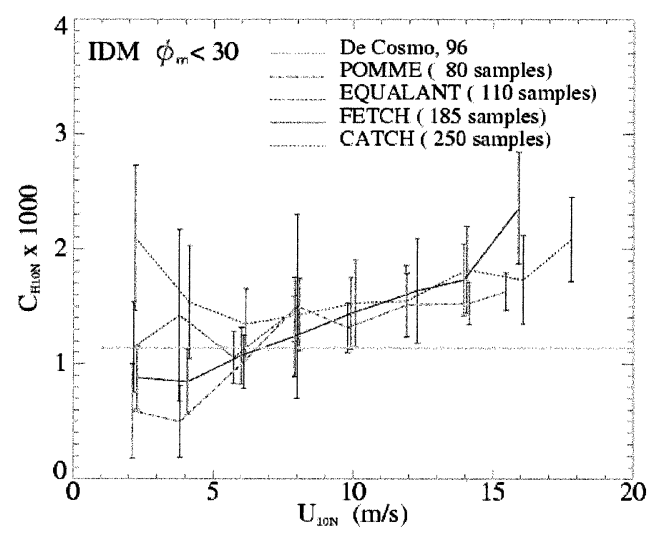

c

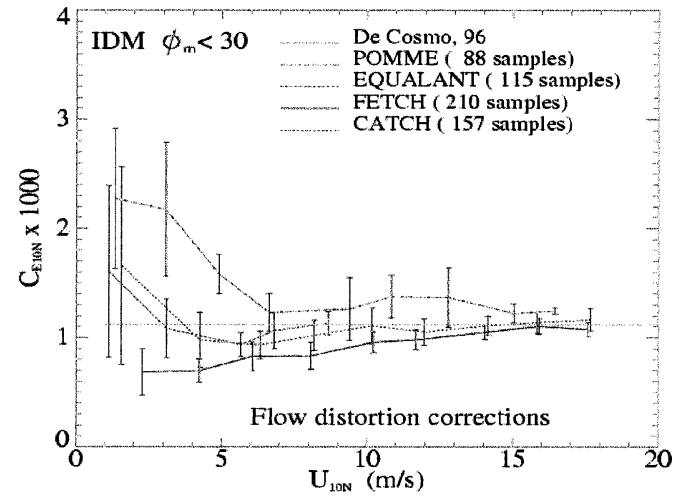

b

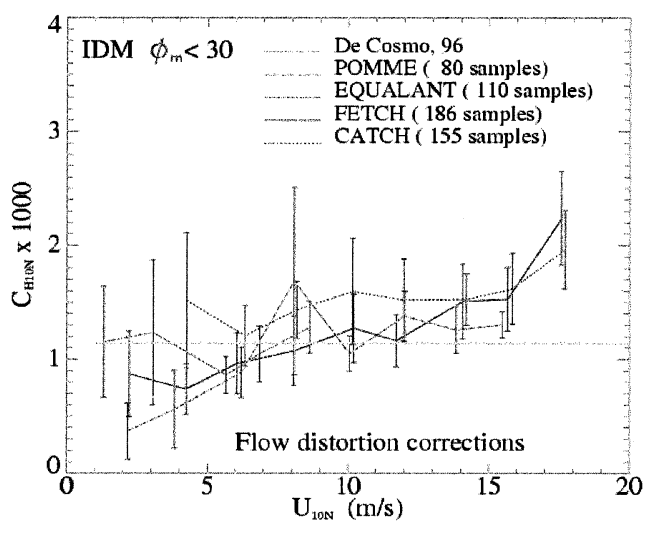

d

FIG. 8. Exchange coefficient (latent and sensible heat flux) by ID as a function of the wind speed. (a) Mean exchange coefficients and associated std dev for every $2 \mathrm{~m} \mathrm{~s}^{-1}$ bin. (b) The same, but after airflow distortion correction. The DeCosmo et al. (1996) value is superimposed. (c), (d) Transfer coefficients for heat without and with airflow correction, respectively.

further confirm results obtained from individual campaigns summarized above: turbulent flux parameterizations obtained on large vessels are strongly biased by the mean part of airflow distortion, which is responsible for most of the discrepancies described in the literature. After correction, drag coefficients are similar within a few percents to other studies using open buoys, thus minimizing airflow distortion (Smith 1980; Drennan et al. 2002) at least for moderate and high wind speeds. This agreement between results of different campaigns is very encouraging and might imply that momentum flux is now well parameterized for relatively well-developed wind seas.

Some more efforts should be made toward understanding low wind speed scatter, as in the case of $\mathrm{CATCH}$, particularly to establish the effect of particular distortion effects at low wind speeds, pitch effects due to swell, sea state effects on air-sea exchanges (Drennan et al. 2002), skin temperature effects affecting the stratification estimates, and finally convection, gustiness parameterizations (Beljaars 1995) and nonstationarity (Geernaert et al. 1986). Indeed, these effects have in- creasing impact at low wind speeds and could explain the significant discrepancies that occur between $\mathrm{CATCH}$ and other experiments at low wind speeds (some EQUALANT99 $C_{\mathrm{DN}}$ have a similar behavior, as seen in Fig. 7b). Note, however, that the high standard deviation observed at low wind is partly explained by the small number of data (less than 10 points for some of them).

Contrary to momentum flux, results for heat flux are rather sparse and this database will hopefully provide progress in heat flux parameterizations. Figure 8 displays the evaporation and heat exchange coefficients, respectively, in Figs. 8a-d. To avoid large scatter due to uncertainties in the air-sea temperature or humidity differences, thresholds were applied to consider only differences greater than $1.5^{\circ} \mathrm{C}$ and $1 \mathrm{~g} \mathrm{~kg}^{-1}$, respectively. Here, SEMAPHORE data were not used because the Lyman-alpha hygrometer data were not processed similarly to the refractometer measurements. Again, there is a large scatter for low wind speeds (below 5$7 \mathrm{~m} \mathrm{~s}^{-1}$ ), but CATCH and FETCH $C_{\mathrm{EN}}$ values look very similar. EQUALANT99 and POMME present slightly higher values, but with the same slope (Fig. 8a). After 


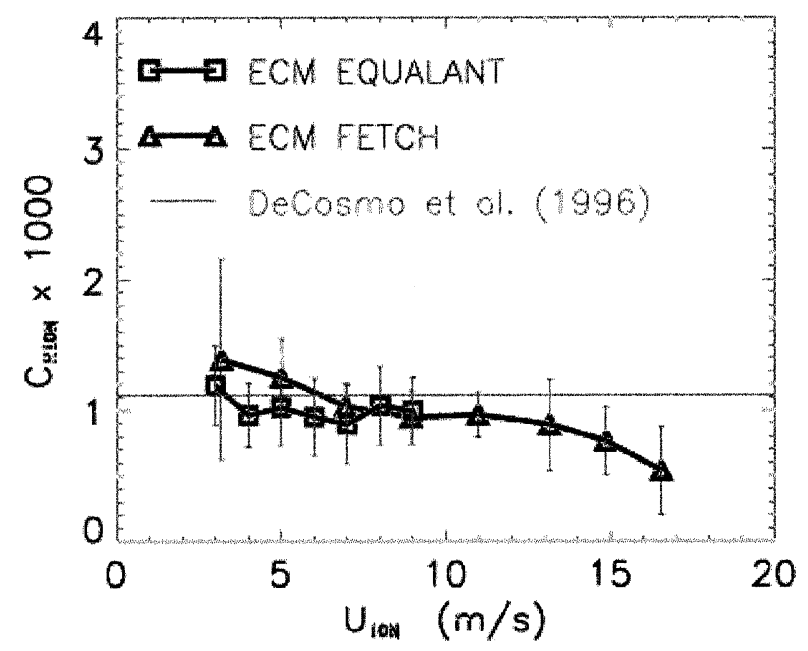

FIG. 9. Transfer coefficients for sensible heat as a function of wind speed normalized to $10-\mathrm{m}$ height and neutral conditions by ECM for FETCH and EQUALANT. The symbols denote the average in 1 or $2 \mathrm{~m} \mathrm{~s}^{-1}$ wind speed bins. Std devs are also displayed.

correction for airflow distortion, results look much more similar, as shown in Fig. 8b: $C_{\mathrm{EN}}$ values decrease at low wind then slightly increase above $5 \mathrm{~m} \mathrm{~s}^{-1}$, contrary to literature parameterizations (Large and Pond 1982; DeCosmo et al. 1996; the latter being superimposed on the dotted line). Similar results were obtained using ECM (PED). As for the drag coefficient, this preliminary result shows the necessity of correcting for airflow distortion, and the high scatter observed at low wind speed requires further analysis.

The results of the sensible heat flux parameterization by ID provides only an order of magnitude estimate due to the low performance of the technique at high frequency: $C_{\mathrm{HN}}$ values as high as $2 \times 10^{-3}$ are obtained (Fig. 8c). After airflow distortion corrections (Fig. 8d), the results appear to be rather consistent for all experiments although we suspect that the wind speed dependency could be due to instrumental noise. Sensible heat flux obtained by ECM for FETCH and EQUALANT99, plotted in Fig. 9, are much more reliable, but with values slightly smaller than those from previous studies such as DeCosmo et al. (1996). This result further suggests that the different methods are complementary and ID and ECM both need to be developed, even on large research vessels, to allow the estimation of all turbulent fluxes. Particular efforts still need to be put for obtaining accurate heat flux parameterizations.

\section{Mesoscale fluxes}

Ship data do not allow investigation of the mesoscale features, in relation with either atmospheric structures or ocean surface structures. At the large scale, the scarcity of in situ data makes it difficult to use only ship data for ocean-atmosphere coupling investigations. Meteorological models are therefore currently used for me- soscale and large-scale studies, and efforts are ongoing to improve satellite-derived information (the SEAFLUX project). At the mesoscale, field campaigns offer the opportunity to analyze the quality of model fields, as well as testing satellite retrieval methods, to produce consistent energy budgets. Our experimental program has included, since its beginning, a study of oceanatmosphere exchanges at the mesoscale, using ship, aircraft, and buoy data; meteorological and ocean models; and satellite observations. The various experiments offered us the possibility to achieve this validation in different meteorological/climatic conditions.

For validating radiative fluxes, direct measurements of the downwelling fluxes are used. For turbulent fluxes, the conclusions of the previous sections led us to use a bulk formula instead of direct measurements:

- ID stresses from all experiments could be used, but consistent estimates of heat fluxes (from ECM) are only available for a few of them;

- The multiexperiment dataset of turbulent fluxes is much smaller than the one obtained using mean meteorological measurements;

- ECM/ID calculations do not differ much from Smith (1980) and DeCosmo et al. (1996) bulk parameterizations, and differences are still a subject of research, particularly for the sensible heat flux.

Using bulk formulas instead of ID fluxes is required to account for airflow distortion (see section 4). However, Eymard et al. (2002) compared bulk fluxes with and without airflow distortion correction on FETCH data. They found that positive and negative distortion effects compensate each other to less than $2 \%$, when taking datasets with wind azimuth within $+/-90^{\circ}$ from the bow.

Thus, the use of bulk formulas allows us to investigate the major causes of discrepancy between mesoscale fields and ship data. In this section, we illustrate this methodology by evaluating the routine European Centre for Medium-Range Weather Forecasts (ECMWF) surface fluxes. Then the need for specific simulations is discussed to address process studies and the impact of model deficiencies on fluxes. Finally, we show the potential and limitations of satellite-derived fluxes.

\section{a. Comparison with model fluxes}

Surface parameters and fluxes predicted by the ECMWF model have been systematically compared with ship measurements for SEMAPHORE, CATCH, FETCH, and EQUALANT99 (Table 4). The ECMWF model is a spectral model. Its approximate grid spacing was $1.125^{\circ}$, until FETCH, then became about $0.5^{\circ}$. Four analyses a day are available, which contain all meteorological parameters obtained from assimilation. Other parameters, such as cloudiness, rain, and surface fluxes, are computed and given in first guesses and forecasts. The turbulent surface flux parameterization is based on 
TABLE 4. Comparison of ECMWF-predicted heat fluxes (6-h integration) with ship measurements. The ship data were averaged over $6 \mathrm{~h}$, and the model fields were interpolated to the location where the ship was in the middle of the time interval. The model-ship difference is given in average for each experiment.

\begin{tabular}{|c|c|c|c|}
\hline & Bias & Rms error & Correlation \\
\hline \multicolumn{4}{|c|}{ Sensible heat flux $\left(\mathrm{W} \mathrm{m}^{-2}\right)$} \\
\hline SEMAPHORE & 6.3 & 34.4 & 0.41 \\
\hline CATCH & 7.5 & 37.9 & 0.87 \\
\hline FETCH & -6.4 & 15.6 & 0.87 \\
\hline EQUALANT & 5.0 & 49.9 & 0.40 \\
\hline \multicolumn{4}{|c|}{ Latent heat flux $\left(\mathrm{W} \mathrm{m}^{-2}\right)$} \\
\hline SEMAPHORE & 21.9 & 59.1 & 0.72 \\
\hline CATCH & 44.4 & 76.6 & 0.79 \\
\hline FETCH & -11.5 & 39.5 & 0.87 \\
\hline EQUALANT & 46.8 & 78.7 & 0.64 \\
\hline \multicolumn{4}{|c|}{ Net solar flux $\left(\mathrm{W} \mathrm{m} \mathrm{m}^{-2}\right)$} \\
\hline SEMAPHORE & -24.2 & 78.3 & 0.85 \\
\hline CATCH & -2.5 & 61.1 & 0.82 \\
\hline FETCH & -9.9 & 59.1 & 0.95 \\
\hline EQUALANT & 39.6 & 162.6 & 0.74 \\
\hline \multicolumn{4}{|c|}{ Net infrared $\left(\mathrm{W} \mathrm{m}^{-2}\right)$} \\
\hline SEMAPHORE & 29.5 & 36.7 & 0.35 \\
\hline $\mathrm{CATCH}$ & 20.6 & 29.7 & 0.75 \\
\hline FETCH & 14.2 & 19.3 & 0.63 \\
\hline EQUALANT & 13.0 & 20.3 & 0.41 \\
\hline \multicolumn{4}{|c|}{ Wind stress $\left(\mathrm{N} \mathrm{m}^{-2}\right)$} \\
\hline SEMAPHORE & 0.005 & 0.05 & 0.74 \\
\hline CATCH & 0.060 & 0.17 & 0.82 \\
\hline FETCH & -0.027 & 0.09 & 0.60 \\
\hline EQUALANT & 0.009 & 0.04 & 0.67 \\
\hline
\end{tabular}

the Monin-Obukhov similarity theory. Over sea, the roughness lengths for momentum, heat, and moisture are expressed following Beljaars (1995). Surface radiative and turbulent flux products are integrated over the last $6 \mathrm{~h}$

The ship fluxes are calculated over 20-min samples and then averaged over the model integration period. The mean ship location within the model integration interval is determined first, then the model flux field is linearly interpolated at the ship location. The same process is applied for radiative fluxes as for turbulent fluxes.

As seen from Table 4, small positive biases are observed for the three experiments in the Atlantic, indicating an overestimate of ECMWF-predicted turbulent fluxes. On the contrary, for FETCH, the model fluxes are underestimated. We also note a poor correlation in low to moderate wind conditions. The model radiative budgets are found to be biased for all the experiments, mainly for the infrared component. Finally the model net heat flux budget is erroneous by $40-90 \mathrm{~W} \mathrm{~m}^{-2}$ in any case.

To further investigate the source of these discrepancies, ship and model atmospheric parameters, (wind, temperature, and humidity) and SST were compared. A rather good agreement was obtained for atmospheric parameters, as indicated by weak mean bias and small rms values (not shown). However, for FETCH, the flux underestimate is mainly due to a strong underestimation of the offshore winds in high pressure conditions. Finally, during SEMAPHORE and CATCH, SST horizontal gradients were observed, associated with strong currents (see section 2). In the vicinity of these fronts, the model SST map, based on Reynolds analysis, does not depict the mesoscale structure of this field, due to its too poor time/space resolution (see Fig. 10b). A similar problem was observed in the coastal area during FETCH. In consequence, the model heat fluxes are strongly biased in these region, although it does not appear on the mean bias and rms error, because of the large number of data. Finally, the major problem in any case is the infrared flux, whose bias is due to the insufficient cloud cover.

\section{b. Specific reanalyses and model simulations}

According to the SEMAPHORE and CATCH results (Kwon et al., 1998; Eymard et al., 1999), SST fronts significantly affect fluxes and the atmospheric boundary layer. As mentioned above, these effects are not properly simulated by operational models. Specific reanalyses and model runs are thus needed to elucidate the role of sea surface fluxes on the atmospheric boundary layer. For instance, Giordani et al. (1998) and Giordani and Planton (2000) demonstrated how surface buoyancy fluxes affect the ageostrophic circulation in the atmospheric boundary layer in the presence of an SST front, by modelling a realistic case of the SEMAPHORE experiment. Strong SST gradients, as observed during $\mathrm{CATCH}$, were also used in a nonhydrostatic simulation to elucidate their influence in the dynamics of an observed atmospheric cyclone (Giordani and Caniaux 2001). These specific process studies demonstrate the need for improving SST fields in meteorological models, in terms of the horizontal gradient. Improvement of flux parameterizations is also required, to correct large biases, as evidenced during $\mathrm{CATCH}$, in particular under strong winds and in case of large instability. Coupling surface fluxes with a wave model can probably help improve the turbulent fluxes. The deficiency of radiative fluxes requires, on its own side, improving the cloud schemes of atmospheric models.

\section{c. Comparison with satellite-retrieved fluxes}

Because of the unsatisfactory results obtained with model fluxes, and the complexity of running specific simulations with assimilation of better resolution data, satellite retrieval methods provide an alternative approach, which might be complementary to models for describing the mesoscale surface fluxes. Nowadays, most methods to retrieve surface fluxes over the ocean from satellites concern solar and longwave fluxes, and the latent heat flux:

- The retrieval of the solar flux is generally based on a 
TABLE 5. Comparison of Meteosat and ship downward radiative fluxes during SEMAPHORE, CATCH, and FETCH. A $0.3^{\circ}$ box centered on the ship location is used, and ship fluxes are averaged over $1 \mathrm{~h}$.

\begin{tabular}{lccccc}
\hline \hline & Meteosat & Ship & Bias & Rms & $\begin{array}{c}\text { Correla- } \\
\text { tion }\end{array}$ \\
\hline Downward infrared flux $\left(\mathrm{W} \mathrm{m}^{-2}\right)$ & & & & \\
FETCH & 307.8 & 303.0 & 4.8 & 17.0 & 0.83 \\
CATCH & 322.9 & 322.6 & 0.3 & 17.0 & 0.84 \\
SEMAPHORE & 374.3 & 370.0 & 4.3 & 15.7 & 0.71 \\
Downward solar flux $\left(\mathrm{W} \mathrm{m}^{-2}\right)$ & & & & \\
FETCH & 390.6 & 402.1 & -11.5 & 62.3 & 0.96 \\
CATCH & 131.8 & 133.1 & -1.3 & 49.9 & 0.84 \\
SEMAPHORE & 315.1 & 304.5 & 10.6 & 58.1 & 0.95 \\
\hline
\end{tabular}

simplified radiative transfer model to make the method applicable to operational geostationary satellite data, as the one proposed by Le Borgne and Marsouin (1988) and Brisson et al. (1994, 1996). The cloud cover effect is taken into account through empirical parameterizations. The longwave flux is much more difficult to retrieve than the solar flux using pure satellite methods: Brisson et al. (1994) applied a bulk formula to meteorological model analyses, in addition to a cloud classification, based on Meteosat visible/ IR images, to get the cloud parameters (prescribed for each cloud type).

- Liu (1984) established the feasibility of latent heat flux estimates over oceans from spaceborne microwave radiometers, using their sensitivity to the atmospheric water vapor content and to the surface wind, the SST being given either by the same instrument or by an infrared radiometer. Since this first attempt, several improvements were proposed to refine the sensitivity to the low-level humidity and to apply the method to a short timescale instead of monthly means: Bourras et al. (2002) developed a statistical relationship between satellite measurements and the surface latent heat flux, established on a global dataset of ECMWF bulk fluxes and satellite data using a neural network technique, which does not require any space/time averaging.

- No direct estimate of the sensible heat flux has been proposed. Several attempts have been made to estimate the air temperature from the other meteorological variables, which can be derived from satellites, as the one of Konda et al. (1996), who used the SST, the surface wind and the atmospheric humidity. Bourras et al. (2002) proposed a simple advection model to physically relate the air temperature in a mesoscale domain to an initial guess (from an operational model), using the surface wind and SST from satellites. This method was successfully applied to SEMAPHORE, leading to an error of $10 \mathrm{~W} \mathrm{~m}^{-2}$ (about $30 \%$ ) on the sensible heat flux.

In the following we present comparisons performed between ship data and Brisson's Meteosat radiative flux-
TABLE 6. Comparison of the surface latent heat flux derived from satellites (SSM/I and AVHRR) with the ship bulk flux. The ship data are averaged over $0.5 \mathrm{~h}$, centered at the satellite overpass.

\begin{tabular}{lccc}
\hline \hline & $\begin{array}{c}\text { Bias } \\
\left(\mathrm{W} \mathrm{m}^{-2}\right)\end{array}$ & $\begin{array}{c}\text { Std dev } \\
\left(\mathrm{W} \mathrm{m}^{-2}\right)\end{array}$ & Correlation \\
\hline SEMAPHORE & 36.3 & 25.8 & 0.87 \\
CATCH & 17.6 & 36.7 & 0.90 \\
FETCH & 22 & 42.4 & 0.85 \\
\hline
\end{tabular}

es, and Bourras latent heat fluxes derived from Special Sensor Microwave Imager (SSM/I) and the Advanced Very High Resolution Radiometer (AVHRR) data.

\section{1) RADIATIVE FLUXES}

METEOSAT-derived surface irradiances were compared with shipdownward shortwave and longwave fluxes during SOFIA, SEMAPHORE, CATCH, and FETCH. Results obtained during CATCH are better than during SOFIA and SEMAPHORE in term of bias error, due to an improved cloud classification (Eymard et al., 1999). In every case, the surface radiation fluxes are much better than those predicted by models (Table 5).

\section{2) LATENT HEAT FLUX}

Microwave radiometer measurements from SSM/I, and SST from AVHRR were used, as described in Bourras et al. (2001). The comparison was performed on SEMAPHORE, CATCH, and FETCH data. Satellitederived latent heat fluxes were shown to have a moderate mean error both in bias and rms (Table 6), when compared to ship fluxes. As shown in Fig. 10, the major advantage of satellite methods (Fig. 10c) with respect to operational meteorological models (Fig. 10d) is that mesoscale features can be better depicted particularly in case of strong SST gradients: the poor quality of SST maps used in models (Fig. 10b) compared to reanalysis (Fig. 10a), is the main cause of error in the model flux, as discussed above.

\section{Conclusions and further studies}

In this study, we presented the methodology we have developed during our research program on turbulent surface fluxes since 1992. Six field experiments were performed, with objectives of gathering data in various meteorological conditions, developing and assessing reliable instrumentation, applying calculations of turbulent fluxes to evaluate bulk parameterizations, and studying the mesoscale variability of fluxes. Along with the study of flux computation methods and parameterizations, we have undertaken analysis of airflow distortion around ships and sensors. Building a flux database to further use field campaign data appeared to us as a need, both for keeping data "alive," and for studying turbulent fluxes in more details. 

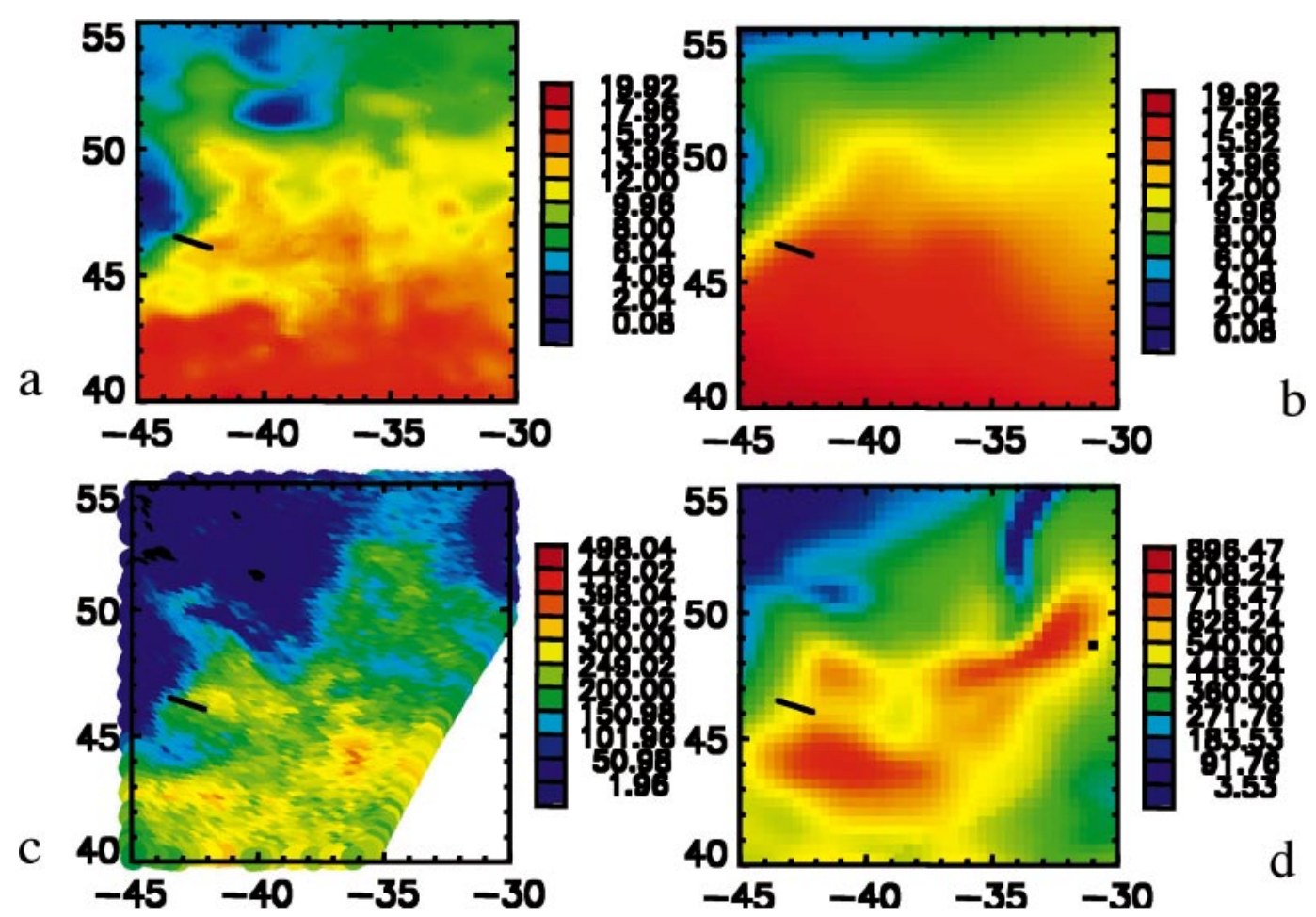

FIG. 10. (a) Reanalyzed SST field for mid-Jan 1997 over the CATCH experimental domain. (b) ECMWF SST analysis over the same area. (c) Surface latent heat flux obtained on 15 Jan 1997 on the CATCH domain using the neural network retrieval (using SSM/I and an SST reanalysis from surface buoys), and (d) the ECMWF bulk flux. Color scales are displayed. The major deficiency of the model is its poorly detailed SST map, which leads to too smooth flux structures along the SST front associated with the North Atlantic Current, compared with the satellite.

The major results of this program are summarized hereafter.

- Instrumentation: While sonic anemometers appear able to work in nearly all conditions and provide reliable measurements for computing the wind stress, measurement of heat fluxes is difficult, because of salt deposits on optical cells of instruments such as the Lyman-alpha hygrometer. We established the feasibility of deriving the turbulent fluctuations of humidity from microwave measurements of the refraction index by using a refractometer; this instrument proved to be very robust to salt and water contamination even in stormy conditions. A motion package was used in conjunction to account for ship motions, allowing us to apply the eddy-correlation method (ECM) on ships in addition to the inertial-dissipation (ID) method.

- The effect of airflow distortion was evidenced by analyzing the sonic wind components, after the correction of ship motion. Two methods were tested in parallel, which have different capabilities and limits: CFD computation, which makes it possible to estimate the distortion for various wind speeds and azimuths; and physical simulations in a water channel, which can be used to distinguish between the respective effects of the ship and of the instrumented mast, as well as to analyze the impact of pitch and roll. The two methods were found to be complementary, and the good agreement of their results makes us confident about applying the derived distortion correction. Two ships were thus analyzed, and results from one are still pending. The major result is that the effect of the mast is more than half the total distortion, due to the location of the sonic anemometer $0.75 \mathrm{~m}$ upstream of the top of the mast and to the presence of electronic boxes 0.5 $\mathrm{m}$ downstream. In addition, pitch has significant impact on the distortion, contrary to roll.

- The same ID computation code was used for all experiments and ECM was used for two of them. Drag and exchange coefficients were computed and plotted versus the mean horizontal wind. Using the same flux code on different datasets is very helpful to benefit from the different conditions encountered, by avoiding discrepancies eventually related to slight differences in thermodynamic or any other constants. The stress is more accurately obtained using ID rather than ECM, because of imperfect correction of the ship motion, and possible turbulent distortion. On the contrary, heat fluxes are better determined using ECM rather than ID, because of the high-frequency noise of the temperature (derived from the sonic speed). Without correction of airflow distortion, drag coefficients tend to differ from one experiment to the other. A clear im- 
provement is obtained after airflow distortion corrections and results confirm that for moderate to strong winds, Smith's (1980) parameterization for the drag coefficient can be used. Despite the lower accuracy of ID for heat fluxes, the various experiments agree with each other that after correction for airflow distortion the Dalton number is nearly constant, at the same value as obtained using ECM, and in agreement with DeCosmo et al. (1996); the Stanton number is found to slightly increase with the wind. The last result is in contradiction with ECM results, and requires further study.

- The experiments were performed in rather different mean conditions, some of them being characterized by horizontal inhomogeneities due to either SST gradient or coastal effects. To study fluxes at the mesoscale, several means were employed: meteorological and ocean circulation models, and satellite retrievals. Operational ECMWF analyses were evaluated over all experiments, showing some systematic discrepancies. Comparison with ship fluxes (turbulent and radiative) revealed that the model overestimates fluxes in the open ocean, whereas the infrared downwelling flux is strongly underestimated. The too smooth SST analysis is one of the major deficiencies of meteorological operational models. Improved simulations were obtained by assimilating all available in situ data. The effect of SST gradients on the atmosphere could thus be evaluated, showing impacts in the boundary layer in any case, and the possible enhancement effect on the development of a frontal system. Satellite retrieval of radiative fluxes gives much more reliable results (bias is lower than $12 \mathrm{~W} \mathrm{~m}^{-2}$ ). Recent progress in retrieving the latent heat flux with microwave and infrared radiometers make it possible to depict the mesoscale flux variations better than models.

Encouraging results were obtained by merging the various experiments in the same database with the same data processing: it is thus possible to validate the current parameterizations in very different conditions (e.g., stable/unstable cases, strong/weak swell, young sea, possible climatic variations, etc.). By correcting datasets from airflow distortion, then combining them, a much wider range of conditions can be explored with a significant number of observations in each case. This allows us to statistically evaluate independent estimates of fluxes, from models and satellites, as well as analyzing particular features. Nevertheless, the field campaigns already performed using the French research vessels cover a limited range of climate/sea state/stability situations; so additional data will be further incorporated in the ALBATROS database in order to better compare ID, ECM, and bulk fluxes, and establish a "universal" parameterization, if feasible. This progress is expected through collaboration between teams, from having the database being open to the scientific community.
Further studies within the ALBATROS project will concern the following:

- Airflow distortion: Up to now, the numerical and physical simulations were performed on two different ships (R/V L'Alatante and Thalassa). A next step will be to study the airflow distortion over the R/V Le Suroît, used from SOFIA (1992) to CATCH (1997). In this study we used preliminary estimates obtained by Moat and Yelland (1996) for a limited range of azimuths and winds, and we will analyze the airflow distortion due to pitch in low wind conditions.

- Flux determination and parameterization: The large scatter observed at wind speeds lower than 5-7 $\mathrm{m} \mathrm{s}^{-1}$ should be further analyzed, because it leads to large flux uncertainties. A number of open questions should be answered to interpret this scatter. In particular, flux parameterization in stable conditions will be investigated, and the possible effect of sea state following the study by Drennan et al. (2002).

- Mesoscale studies: Further validation will be performed concerning model fluxes and satellite techniques for estimating fluxes at the mesoscale and large scale. In particular, POMME ship fluxes will be extensively used to determine whether or not model bias are systematic or vary during the year. Another interest of this experiment is that a precise surface heat budget can be determined thanks to the four repeated mesoscale surveys performed over one year in the area. The determination of the mesoscale heat budget by mixing satellite data and model outputs will tell us if the heat budget can be closed and with what uncertainty. Satellite retrieval methods still need further development to characterize errors, and provide reliable net heat budgets. Feasibility of combining retrievals of radiative, latent, and sensible heat fluxes to obtain the energy budget with an acceptable accuracy will be investigated.

Acknowledgments. We thank all the officers and crew members who took part in the various campaigns and ensured their success. We are grateful toward all the technical and scientific teams that, more or less, implied the realization of the experiments: the teams $4 \mathrm{M}$ and STAR from the CNRM, in particular, P. Bessemoulin, the teams of the CETP, and the Direction Technique of INSU. We thank all the ship team leaders who contributed to acquire the datasets, in particular L. Prieur from the Oceonographic Laboratory of Villefranche sur Mer. This work has been supported by INSU/CNRM, MétéoFrance, and SHOM.

\section{REFERENCES}

Albrecht, B. A., C. S. Bretherton, D. Johnson, W. H. Schubert, and A. S. Frisch, 1995: The Atlantic stratocumulus transition experiment-ASTEX. Bull. Amer. Meteor. Soc., 76, 889-903. Anctil, F. M. A. Donelan, and H. C. Graber, 1994: Eddy-correlation 
measurements of air-sea from a discus buoy. J. Atmos. Oceanic Technol., 11, 1144-1150.

Beljaars, A. C. M., 1995: The parameterization of surface fluxes in large scale models under free convection. Quart. J. Roy. Meteor. Soc., 121, 255-270.

Blanc, T. V., 1986: Superstructure flow distortion corrections for wind speed and direction measurements made from Tarawa Class (LHA1-LHA5) ships. Naval Research Laboratory, NRL Rep. 9005, 20 pp.

_ - , 1987: Superstructure flow distortion corrections for wind speed and direction measurements made from Virginia Class (CGN38CGN41) ships. Naval Research Laboratory, NRL Rep. 9026, 24 pp.

Bourras, D., L. Eymard, and W. T. Liu, 2001: A neural network to estimate the latent heat flux over oceans from satellite observations. Int. J. Remote Sens., 23, 2405-2423.

,,------ , and H. Dupuis, 2002: An integrated approach to estimate instantaneous near-surface air temperature and sensible heat flux fields during the SEMAPHORE experiment. J. Appl. Meteor., 41, 241-252.

Brisson, A., P. Le Borgne, A. Marsouin, and T. Moreau, 1994: Surface irradiances calculated from Meteosat sensor data during SOFIA/ ASTEX. Int. J. Remote Sens., 15, 197-204.

- - , - - and - - 1996: Retrieval of air-sea interface parameters from Meteosat data. Proc. 1996 Meteorological Satellite Data Users Conf., Wien, Austria, EUMETSAT, 229-238.

Brut, A., A. Butet, S. Planton, P. Durand, and G. Caniaux, 2002a: Influence of the airflow distortion on air-sea flux measurements aboard research vessels: Results of physical simulations applied to the EQUALANT99 experiment. Preprints, 15th Symp. on Boundary Layers and Turbulence, Wageningen, Netherlands, Amer. Meteor. Soc., 147-150.

- - , D. Legain, P. Durand, Y. Prigent, G. Bouhours, T. Douffet, and J. Barillé, 2002b: Use of the REA technique to measure scalar fluxes on ground-based and mobile platform. Preprints, 15th Symp. on Boundary Layers and Turbulence, Wageningen, Netherlands, Amer. Meteor. Soc., 12-15.

Businger, J. A., 1972: Turbulent transfer in the atmospheric surface layer. Workshop in Micrometeorology, Haugen, Ed., 67-100.

Butet, A., 2001: Simulation du vent autour du N.O. La Thalassa. Note 23, GMEI, Météo-France.

- - , 2002: Simulation du vent autour du N.O. L'Atalante. Note 24, GMEI, Météo-France.

Caniaux, G., and S. Planton, 1998: A 3D ocean mesoscale simulation using data from the SEMAPHORE experiment: Mixed layer heat budget. J. Geophys. Res., 103 (C11), 25 081-25 099.

- - , L. Prieur, H. Giordani, F. Hernandez, and L. Eymard, 2001: Observation of the circulation in the Newfoundland Basin in winter 1997. J. Phys. Oceanogr., 31, 689-710.

Curry, J. A., 2000: SEAFLUX: Ocean surface turbulent flux project. [Available online at http://paos.colorado.edu/ curryja/ocean/ home.html.]

DeCosmo, J., K. B. Katsaros, S. D. Smith, R. J. Anderson, W. A. Oost, K. Bumke, and H. Chadwick, 1996: Air-sea exchange of sensible heat and water vapor: The HEXOS results. J. Geophys. Res., 101, 12 001-12016.

Delahaye, J. Y., and Coauthors, 2001: A new ship borne microwave refractometer for estimating the evaporation flux at the sea surface. J. Atmos. Oceanic Technol., 18, 459-475.

Dupuis, H., P. K. Taylor, A. Weill, and K. B. Katsaros, 1997: The inertial dissipation method applied to derive momentum fluxes over the ocean during the SOFIA/ASTEX and SEMAPHORE experiments with low to moderate wind speeds. J. Geophys. Res., 102 (C9), $21115-21129$.

- - , C. Guérin, A. Weill, and D. Hauser, 1999: Heat fluxes by the inertial dissipation method during FETCH. Proc. Symp. on the Wind-Driven Air-Sea Interface, Sydney, Australia, School of Mathematics, University of New South Wales, 297-304.

,---- , D. Hauser, A. Weill, P. Nacass, W. Drennan, S. Cloché, and H. Graber, 2002: Impact of flow distortion corrections on turbulent fluxes estimated by the inertial dissipation method during the FETCH experiment on R/V L'Atalante. J. Geophys. Res., in press.

Durand, P., H. Dupuis, D. Lambert, B. Benech, A. Druillet, K. Katsaros, P. K. Taylor, and A. Weill, 1998: Comparison of sea surface fluxes measured by instrumented aircraft and ship during SOFIA and SEMAPHORE experiments. J. Geophys. Res., 103 (C11), $25125-25136$.

Drennan, W., H. Graber, M. A. Donelan, and D. Hauser, 2002: On the wave age dependence of wind stress over pure wind seas. J. Geophys. Res., in press.

Eymard, L., 1998: Introduction to the special section: The SEMAPHORE experiment. J. Geophys. Res., 103 (C11), 25 005-25 008.

- - , and Coauthors, 1996: Study of the air-sea interactions at the mesoscale: The SEMAPHORE experiment. Ann. Geophys., 14, 986-1015.

- - , and Coauthors, 1999: Surface fluxes in the North Atlantic Current during the CATCH/FASTEX experiment. Quart. J. Roy. Meteor. Soc., 125, 3563-3599.

- - , A. Weill, D. Bourras, and C. Guérin, 2002: Use of ship mean data for validating model and satellite flux fields during the FETCH experiment. J. Geophys. Res., in press.

Fairall, C. W., J. E. Hare, E. F. Bradley, A. A. Gratchev, and J. B. Edson, 2001: Preliminary results from the ETL open ocean airsea flux database. Extended Abstracts, WCRP/SCOR Workshop on Intercomparison and Validation of Ocean-Atmosphere Flux Fields, Washington, DC, WCRP/SCOR, 26-29.

Garatt, J. R., 1992: The Atmospheric Boundary Layer. Cambridge University Press, $316 \mathrm{pp}$.

Geernaert, G. L., K. B. Katsaros, and K. Richter, 1986: Variations of the drag coefficient and its dependence on sea state. J. Geophys. Res., 91, 7667-7679.

Giordani, H., and S. Planton, 2000: Modeling and analysis of ageostrophic circulation over the Azores oceanic front during the SEMAPHORE experiment. Mon. Wea. Rev., 128, 2270-2287.

- - , and G. Caniaux, 2001: Sensitivity of cyclogenesis to sea surface temperature in the Northwestern Atlantic. Mon. Wea.Rev., 129, 1273-1295.

- - , S. Planton, B. Benech, and B. H. Kwon, 1998: Atmospheric boundary layer response to sea surface temperatures during the SEMAPHORE experiment. J. Geophys. Res., 103 (C11), 25047 25060.

Gouriou, Y., and Coauthors, 2001: Deep circulation in the equatorial Atlantic Ocean. Geophys. Res. Lett., 28, 819-822.

Graber, H. C., E. A. Terray, M. A. Donelan, W. M. Drennan, J. C. van Leer, and D. B. Peters, 2000: ASIS: A new air-sea interaction spar buoy: Design and performance at sea. J. Atmos. Oceanic Technol., 17, 708-720.

Hare, J. E., P. O. Persson, C. W. Fairall, and J. B. Edson, 1999: Behavior of Charnock's relationship for high wind conditions. Preprints, 13th Conf. on Boundary Layers and Turbulence, Dallas, TX, Amer. Meteor. Soc., 252-255.

Hauser, D., H. Dupuis, X. Durrieu de Madron, C. Estournel, C. Flamant, J. Pelon, P. Queffeulou, and J. M. Lefèvre, 2000: La campagne FETCH: Une expérience pour l'étude des échanges océan/ atmosphère dans les conditions côtières du Golfe du Lion. 8ème Série n²9, La Météorologie.

- - , and Coauthors, 2002: The FETCH experiment: An overview. J. Geophys. Res., in press.

Joly, A., and Coauthors, 1999: Overview of the field phase of the Fronts and Atlantic Storm-Track EXperiment (FASTEX) project. Quart. J. Roy. Meteor. Soc., 125, 3131-3163.

Josey, S. A., 2001: A comparison of ECMWF, NCEP-NCAR, and SOC surface heat fluxes with moored buoy measurements in the subduction region of the northeast Atlantic. J. Climate, 14, 1780-1789.

Katsaros, K. B., M. A. Donelan, and W. M. Drennan, 1993: Flux measurement from a swath ship during SWADE. J. Mar. Syst. 12, 464-482.

Komen, G., P. A. E. M. Janssen, V. Makin, and W. Oost, 1998: On 
the sea state dependence of the Charnock parameter. Global Atmos.-Ocean Syst., 5, 367-388.

Konda, M., N. Imasato, and A. Shibata, 1996: A new method to determine near-sea surface air temperature by using satellite data. J. Geophys. Res., 101 (C6), 14 349-14 360.

Kwon, B. H., B. Bénech, D. Lambert, P. Durand, A. Druilhet, H. Giordani, and S. Planton, 1998: Structure of the marine atmospheric boundary layer over an oceanic thermal front (SEMAPHORE experiment). J. Geophys. Res., 103, 25 159-25 180.

Large, W. G., and S. Pond, 1982: Sensible and latent heat flux measurements over the ocean. J. Phys. Oceanogr., 12, 464-482.

Larsen, S. E., and Coauthors, 2000: AUTOFLUX: An autonomous flux package for measuring the air-sea flux momentum, heavy, water vapour and carbon dioxide. Proc. EUROCEAN 2000 Conf., Hamburg, Germany.

Le Borgne, P., and A. Marsouin, 1988: Détermination du flux ondes courtes incident à la surface. Mise au point d'une méthode opérationnelle à partir des données du canal visible de Meteosat. La Météorologie, 20, 9-19.

Liu, W. T., 1984: Estimation of latent heat flux with SEASAT-SMMR A case study in North Atlantic. Large-Scale Oceanographic Experiments and satellites, C. Gautier and M. Fieu, Eds., Reidel, 205-221.

Moat, B. I., and M. J. Yelland, 1996: Airflow over Le Suroît using the CFD package VECTIS. Southampton Oceanography Centre, SOC Internal Document No. 3, 24 pp.

Perrier, M., and A. Butet, 1988: Veine hydraulique du CNRM, fonctionnement en écoulement neutre. Etablissement d'Etudes et de Recherches Météorologiques, Rep. 216.
Renfrew, I. A., G. W. K. Moore, P. S. Guest, and K. Bumke, 2002: A comparison of surface layer and surface turbulent flux observations over the Labrador Sea with ECMWF analyses and NCEP reanalyses. J. Phys. Oceanogr., 32, 383-400.

Servain, J., A. J. Busalacchi, M. McPhaden, A. D. Moura, G. Reverdin, M. Vianna, and S. E. Zebiak, 1998: A Pilot Research Moored Array in the Tropical Atlantic (PIRATA). Bull. Amer. Meteor. Soc., 79, 2019-2031.

Smith, S. D., 1980: Wind stress and heat fluxes over the ocean in gale force winds. J. Phys. Oceanogr., 10, 709-726.

- - , M. A. Bourassa, and R. J. Sharp, 1999: Establishing more truth in true winds. J. Atmos. Oceanic Technol., 16, 939-952.

Weill, A., and Coauthors, 1995: SOFIA 1992 experiment during ASTEX. Atmos.-Ocean Syst., 3, 355-395.

Weller, R. A., and S. P. Anderson, 1996: Surface meteorology and air-sea fluxes in the western equatorial Pacific warm pool during the TOGA Coupled Ocean-Atmosphere Response Experiment. J. Climate, 9, 1959-1990.

Yelland, M. J., P. K. Taylor, I. E. Consterdine, and M. H. Smith, 1994: The use of the inertial dissipation technique for shipboard wind stress determination. J. Atmos. Oceanic Technol., 11, 10931108

- - , B. I. Moat, P. K. Taylor, R. W. Pascal, J. Hutchings, and V. C. Cornell, 1998: Wind stress measurements from the open ocean corrected for airflow distortion by the ship. J. Phys. Oceanogr., 28, 1511-1525.

,,---- R. W. Pascal, and D. I. Berry, 2002: CFD model estimates of the airflow distortion over research ships and the impact on momentum flux measurements. J. Atmos. Oceanic Technol., 19, 1477-1499. 